\title{
Physicochemical and Adsorption Characteristics of Divinylbenzene-co-Triethoxyvinylsilane Microspheres as Materials for the Removal of Organic Compounds
}

\author{
Alicja Bosacka *D, Małgorzata Zienkiewicz-Strzalka (D, Małgorzata Wasilewska, Anna Derylo-Marczewska * \\ and Beata Podkościelna (iD)
}

Citation: Bosacka, A.; Zienkiewicz-Strzalka, M.; Wasilewska, M.; Derylo-Marczewska, A.; Podkościelna, B. Physicochemical and Adsorption Characteristics of Divinylbenzene-co-Triethoxyvinylsilane Microspheres as Materials for the Removal of Organic Compounds Molecules 2021, 26, 2396. https:// doi.org/10.3390/molecules26082396

Academic Editor:

Bhanu P. S. Chauhan

Received: 27 February 2021

Accepted: 16 April 2021

Published: 20 April 2021

Publisher's Note: MDPI stays neutral with regard to jurisdictional claims in published maps and institutional affiliations.

Copyright: (c) 2021 by the authors. Licensee MDPI, Basel, Switzerland. This article is an open access article distributed under the terms and conditions of the Creative Commons Attribution (CC BY) license (https:// creativecommons.org/licenses/by/ $4.0 /)$
Institute of Chemical Sciences, Faculty of Chemistry, Maria Curie-Sklodowska University, Maria Curie-Sklodowska Sq. 3, 20-031 Lublin, Poland; malgorzata.zienkiewicz@poczta.umcs.lublin.pl (M.Z.-S.); malgorzata.wasilewska@poczta.umcs.lublin.pl (M.W.); beatapod@poczta.umcs.lublin.pl (B.P.)

* Correspondence: alicja.bosacka@poczta.umcs.lublin.pl (A.B.); annad@hektor.umcs.lublin.pl (A.D.-M.); Tel.: +48-81-53-777-66 (A.D.-M.)

Abstract: In this work, organic-inorganic materials with spherical shape consisting of divinylbenzene (DVB) and triethoxyvinylsilane (TEVS) were synthesized and investigated by different complementary techniques. The obtained microspheres may be applied as sorbent systems for the purification of organic compounds from water. The hybrid microspheres combine the properties of the constituents depending on the morphologies and interfacial bonding. In this work, the influence of the molar ratio composition of crosslinked monomer (DVB) and silane coupling agent (TEVS) (DVB:TEVS molar ratios: 1:2, 1:1 and 2:1) on the morphology and quality of organic-inorganic materials have been examined. The materials were analysed using small angle X-ray scattering (SAXS) analysis, low-temperature nitrogen sorption, scanning electron microscopy (SEM) and Fourier transform infrared spectroscopy (FTIR) to provide information on their structural and surface properties. Moreover, thermal analysis was performed to characterize the thermal stability of the studied materials and the adsorbent-adsorbate interactions, while adsorption kinetic studies proved the utility of the synthesized adsorbents for water and wastewater treatment.

Keywords: polymer-inorganic materials; nanostructures; microspheres; adsorption kinetics

\section{Introduction}

The development of industry and technology has contributed to the increase in demand for materials with well-defined characteristics and combining several features of different solids in one type of structure [1-3]. Hybrid organic-inorganic materials are the answer to the growing needs of the material market $[4,5]$. One of the most important actual challenges in designing these combined systems is how to keep or increase the best properties of each component while rejecting or decreasing their limitations [6]. Organic-inorganic materials based on a polymer matrix are some of the most frequently obtained types of hybrid systems because of their ease of synthesis and further modification $[7,8]$.

Generally, polymers have many desirable physical properties including tensile strength, modulus, toughness, or viscoelasticity. Nevertheless, because of their worse mechanical and thermal properties in comparison to metals or ceramics, numerous polymers have restricted use in engineering applications $[9,10]$. The mechanical and thermal properties of polymers can be improved by combining them in organic-inorganic systems. The connection between the polymer and the inorganic phase improves its strength and toughness. Moreover, the inorganic component provides the mechanical and thermal stability and usually leads to many other desired chemical and physical properties of the hybrid materials [11-15].

Hybrid organic-inorganic materials with spherical shapes (microspheres) can be prepared by different methods (polymerization, extraction, dispersion, solvent evaporation or 
emulsion techniques). In this work the suspension polymerization method was used to obtain polymer-silane microspheres. Generally, suspension polymerization is a reaction in which a monomers mixture with an initiator is dispersed in a continuous aqueous phase with the addition of a small amount of a suspension agent (stabilizer) [16-18]. The method as well as conditions of synthesis reaction have an influence on the properties of polymerinorganic microspheres. The adsorption properties of hybrid microspheres result from their porous structures which develop during the polymerization reaction. The amounts, shapes and sizes of pores depend on pore-forming diluents applied to expand the polymer matrix, however, the major factor in developing the surface area is the crosslinking agent (the higher amount of crosslinker, the higher the surface area) [19-22].

Water is an essential compound used for many purposes, from drinking to industrial processes. Both drinking and industrial water must in many cases be treated before use due to the presence of various harmful contaminants [23-25]. Among the different wastewater treatment methods, adsorption is widely used because of its simplicity, good treatment efficiency, the availability of a wide variety of adsorbents, and relatively low costs. Aliphatic or aromatic organic substances including aldehydes, amines, nitrides, pesticides, pharmaceuticals and dyes are generally compounds that are difficult to decompose in water [26-32]. Therefore, the development of effective, inexpensive and selective sorbents is a crucial issue. Traditional sorbents may have many limitations: they can be susceptible to contamination and microbial growth, they may have poor mechanical and thermal stability, not enough efficiency and short life-time. The solution is to combine several solids in one in order to obtain materials with improved properties [25,29].

Adsorption processes of different aromatic compounds from solutions have been widely studied to find the dependencies between the sorption effectiveness and the properties of the adsorbate and adsorbent. Generally, the adsorption effectiveness should be treated as a result of the combined properties of the adsorbent, adsorbate and solvent as well as the parameters of the adsorption process. The affinity of various substances for solid materials depends on many factors: the structure and size of the adsorbate molecules, type of functional groups, solubility, interactions (mainly intra- or inter- molecular hydrogen bonds), as well as the properties of the solvent, and the surface and structure of the adsorbents. Therefore, data interpretation is a complex matter [33,34].

In this work, divinylbenzene-co-triethoxyvinysilane (DVB-TEVS) microspheres were synthesized by a copolymerization reaction at three different molar ratios 1:2, 1:1 and 2:1, in which the DVB is the organic phase and TEVS, an inorganic one. The divinylbenzene molecule has an aromatic ring linked with two vinyl groups structure (Figure 18b) while the TEVS used as a crosslinking agent is an inorganic compound with formula $\left(\mathrm{Si}\left(\mathrm{OCH}_{3}\right)_{3} \mathrm{CH}_{2}\right)$ (Figure 18a). Organic-inorganic materials similar to DVB-TEVS are described in the literature, however, there is still an ongoing search for new materials showing high efficiency and selectivity towards various groups of pollutants. The proposed organic-inorganic microspheres show promising properties, especially as adsorbents for the removal of heavy ions and organic compounds from aqueous solutions and selective materials for solidphase extraction techniques, because of their well-developed porous structures. Also, these materials are characterized by good thermal resistance [35-42].

The obtained samples were analyzed by various techniques. Small angle X-ray diffraction analysis (SAXS) provided detailed information about the structure of these microspherical complex systems. To strengthen and confirm the correctness of the SAXS analysis, these results were correlated and completed with low-temperature nitrogen sorption analysis, scanning electron microscopy (SEM) and also Fourier transform infrared spectroscopy /attenuated total reflection (FTIR/ATR) spectroscopy. In addition, a thermal analysis was conducted to assess the thermal properties of the obtained materials. Moreover, regarding the application in water remediation systems the adsorption properties of the hybrid materials were investigated by kinetic studies. 


\section{Results and Discussion}

2.1. Materials Characteristics

\subsubsection{SEM Studies}

The effect of the proportions of reacting TEVS and DVB components on the properties of the newly synthesized materials was investigated via scanning electron microscopy (SEM) and further correlated and developed by SAXS and nitrogen adsorption/desorption analysis. It was found that the copolymerization of divinylbenzene with triethoxyvinylsilane by the suspension polymerization method led to obtaining well-defined polymericinorganic microspheres. The SEM results presented in Figure 1 show low and high magnification images of the final microspheres.

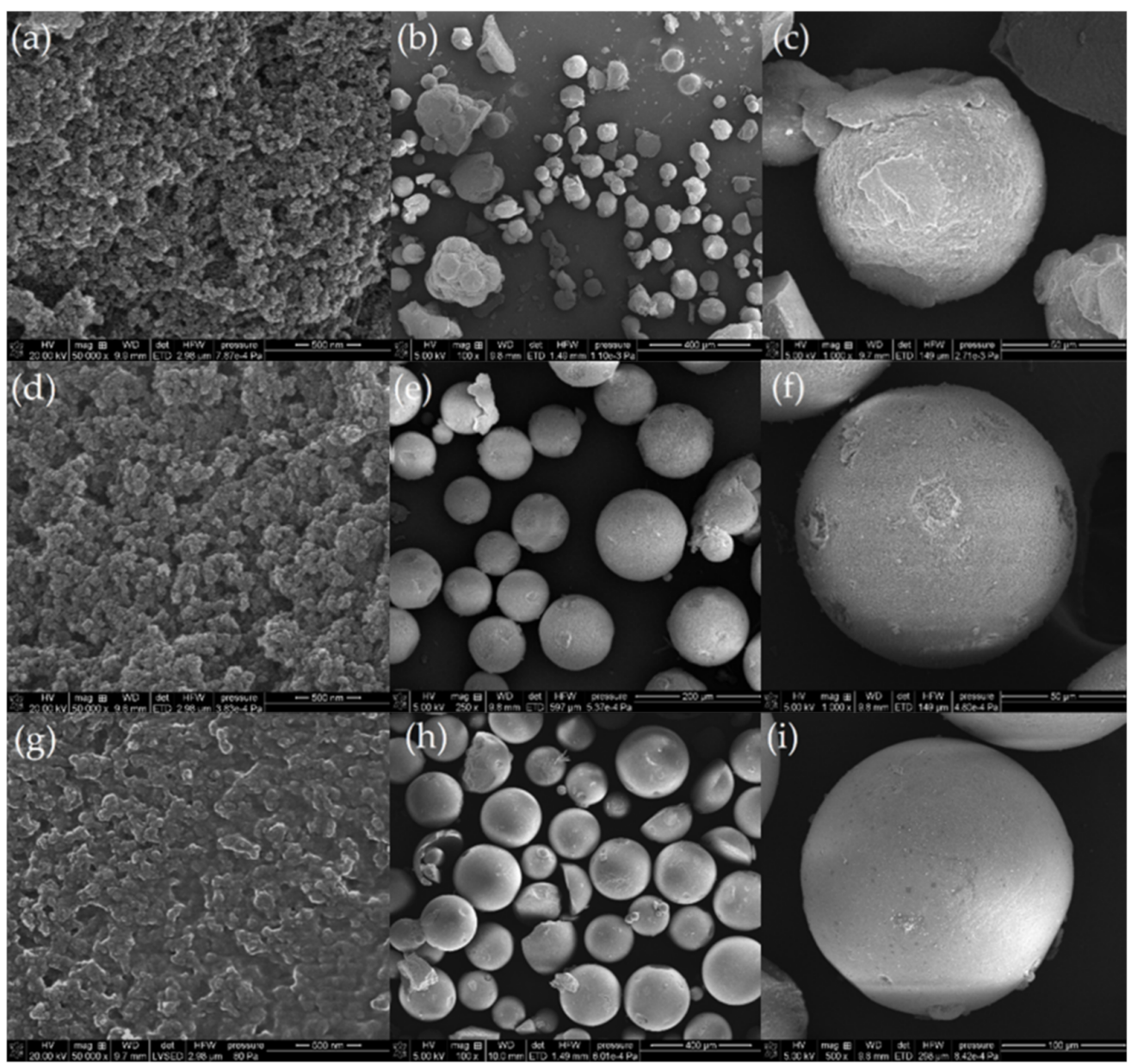

Figure 1. SEM images of DVB:TEVS = 1:2 (a-c), DVB:TEVS $=1: 1$ microspheres $(\mathbf{d}-\mathbf{f})$ and DVB:TEVS $=2: 1$ microspheres $(\mathbf{g}-\mathbf{i})$ in different magnification.

The particles of the studied inorganic-organic materials have spherical shapes with gradually changing surface smoothness and diameters ranging from $50 \mu \mathrm{m}$ to $200 \mu \mathrm{m}$. Moreover, the applied polymerization conditions yielded about $80 \%$ microspheres in the range of 100-150 $\mu \mathrm{m}$. Depending on the molar ratio of components in the reaction mixture, differences in the morphology and porosity of the final microspheres were observed. When the ratio of organic to inorganic phases was 1:2, the spherical morphology of the material is disturbed with many deviations from the ideal spherical form, the material is heterogeneous, and several defects are observed (Figure $1 \mathrm{a}-\mathrm{c}$ ). The most regular shape, the highest homogeneity, and the lowest porosity were observed for the DVB:TEVS = 2:1 sample (Figure $1 \mathrm{~g}-\mathrm{i}$ ). In this case, the surface of the spheres is the most uniform and smooth. The DVB:TEVS = 1:1 sample, shows intermediate morphological and pore prop- 
erties in comparison to the materials synthesized at proportions DVB:TEVS $=2: 1$ and DVB:TEVS = 1:2 (Figure 1d-f).

The DVB:TEVS $=1: 2$ spheres are characterized by the most developed surface with the highest degree of roughness. The observed differences in the surface layers of the polymer spheres depending on the fraction of individual components indicate a clear pore-forming nature of the inorganic TEVS component and its role in the formation of an extensive surface on the created materials. The use of a silane coupling agent with a branched crosslinking nature may be responsible for the assembly of an increased porous network. The TEVS contains three ethoxy groups that occupy an area close to the $\mathrm{Si}$ atoms, thus limiting the formation of a polymer network in their vicinity and creating a porous system. In this case, the TEVS monomer is responsible for the observed hierarchical roughness and surface vinyl terminations $[43,44]$. The DVB monomer and crosslinker with its simple unidirectional structure guide the materials into a more monolithic form $[45,46]$.

Depending on the need to create materials for various applications (catalyst supports, adsorbents), strict control of the number of ingredients of different natures has a significant impact on the ultimate morphology and allows obtaining more or less heterogeneous and porous materialstructures.

\subsubsection{FTIR/ATR Analysis}

FTIR/ATR spectroscopy was applied to assess the advancement in the phase bonding of the organic-inorganic microspheres. The building of dual systems is associated with the content of both polymeric as well as silane phases. Therefore, the characteristic vibrations from divinylbenzene and triethoxyvinylsilane have been observed (Figure 2). The spectra show bands at $1000-1110 \mathrm{~cm}^{-1}$ associated with the asymmetrical stretching vibrations of $\mathrm{Si}-\mathrm{O}-\mathrm{C}$ groups, which confirm the incorporation of TEVS into the polymeric structure of the synthesized material. This peak is not observed for divinylbenzene (Figure S1, Supplementary Material). The TEVS introduction into the polymeric phase has been found for all studied materials. However, the peak with the highest intensity is observed for the sample with the highest amount of triethoxyvinylsilane [33]. The existence of stretching bonds $\mathrm{C}-\mathrm{H}$ of methyl $\left(-\mathrm{CH}_{3}\right)$, ethyl $\left(-\mathrm{CH}_{2}-\mathrm{CH}_{3}\right) \sim 2900 \mathrm{~cm}^{-1}$ and vinyl groups $\left(-\mathrm{CH}=\mathrm{CH}_{2}\right)$ $\sim 3080 \mathrm{~cm}^{-1}$ and $\sim 2998 \mathrm{~cm}^{-1}$ and aromatic ring of divinylbenzene $\sim 3020 \mathrm{~cm}^{-1}$ are observed. The peak intensity of aromatic ring for DVB:TEVS materials is associated with the sample composition. For DVB:TEVS = 1:2 this peak intensity is the lowest. The stretching vibrations of $\mathrm{C}=\mathrm{C}$ from vinyl groups are found at $1650 \mathrm{~cm}^{-1}$. The ring stretches of aromatic ring are visible at 1600, 1500 and $1450 \mathrm{~cm}^{-1}$, respectively. The deformation vibrations of methyl and ethyl groups are observed in the range of $1470-1350 \mathrm{~cm}^{-1}$. Moreover, in the range of $900-650 \mathrm{~cm}^{-1}$ is possible to see deformation bands of C-H groups at benzene ring, therefore, the presence out of plane ring and $\mathrm{H}$ bending vibrations at 695 and $750 \mathrm{~cm}^{-1}$ is detected. Besides, the out of plane bending and twisted vibrations of vinyl groups at 908 and $991 \mathrm{~cm}^{-1}$ are observed [36-42]. 


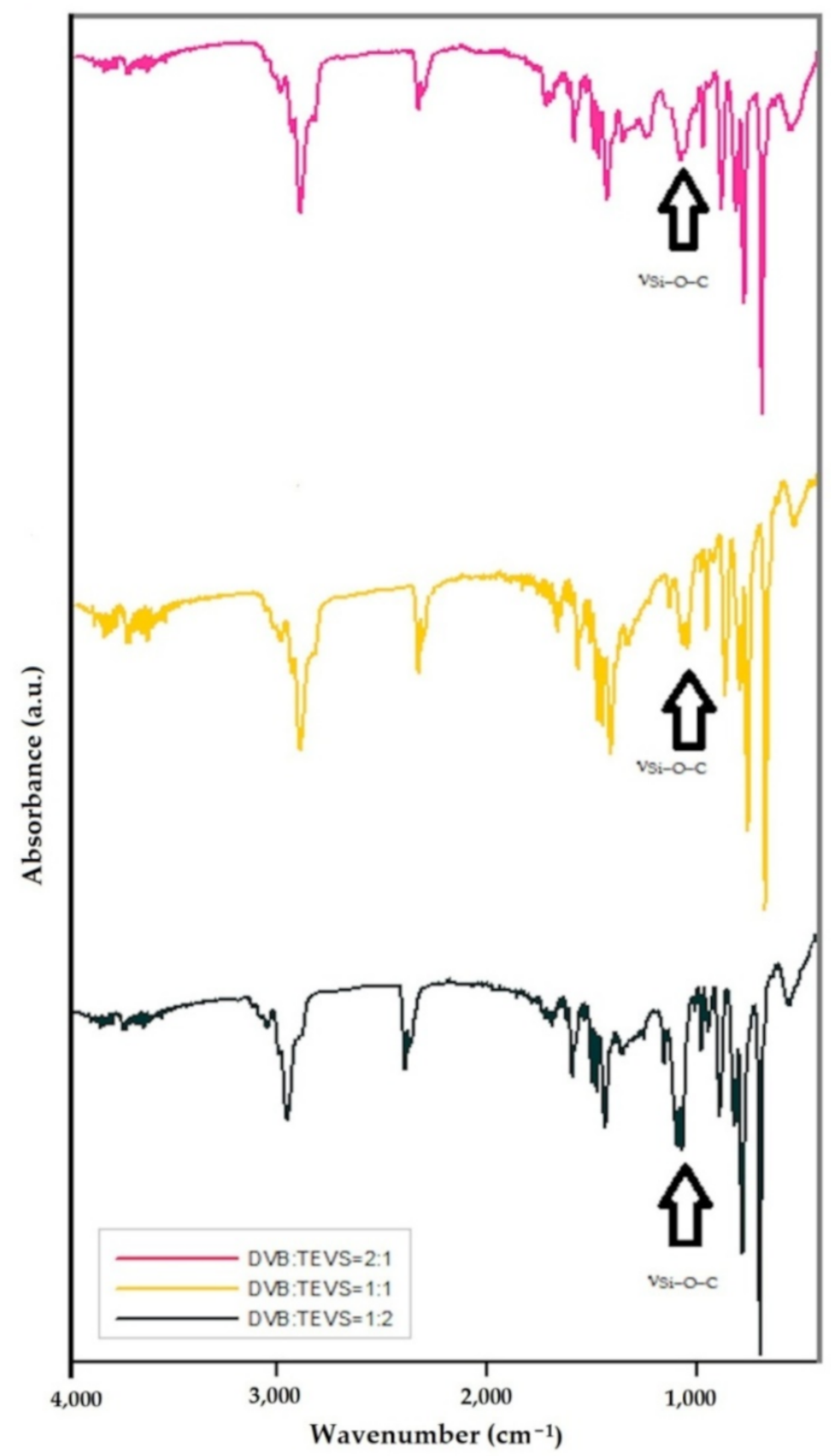

Figure 2. FTIR/ATR spectra for DVB:TEVS materials with phase ratios: 2:1, 1:1 and 1:2.

\subsubsection{SAXS Investigation}

Investigation of new materials requires the detailed analysis of structural aspects due to their importance in adsorption/desorption or immobilization processes. In this part, the microstructure of organic-inorganic materials was investigated by small-angle $\mathrm{X}$-ray scattering. Table 1 includes the investigated materials and selected microstructure parameters determined from SAXS analysis. 
Table 1. Structural parameters of the investigated organic-inorganic systems.

\begin{tabular}{|c|c|c|c|c|c|c|c|c|c|c|c|}
\hline \multirow{2}{*}{ Sample } & \multirow{2}{*}{$\mathbf{R}^{\mathrm{a}}[\mathbf{A}]$} & \multirow{2}{*}{$\begin{array}{c}\text { PDDF }^{b} \\
\text { [Å] }\end{array}$} & \multirow{2}{*}{ 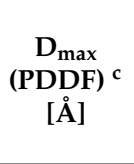 } & \multicolumn{2}{|c|}{$\mathrm{R}_{\mathrm{g}}[\AA ̊]$ (Sphere) $^{\mathrm{d}}$} & \multicolumn{4}{|c|}{$\begin{array}{c}\text { Porod } \\
\text { Approximation }\end{array}$} & \multicolumn{2}{|c|}{$\begin{array}{c}\text { Specific Surface } \\
\text { Area }\end{array}$} \\
\hline & & & & PDDF $^{e}$ & Guinier $\mathrm{f}$ & $\mathrm{K}^{\mathrm{g}}$ & {$\left[\begin{array}{l}Q^{h} \\
{\left[\hat{A}^{-1}\right]}\end{array}\right.$} & $\mathrm{C}_{0}{ }^{\mathrm{i}}$ & $\begin{array}{c}\mathrm{S} / \mathrm{V} \\
{\left[\AA^{-1}\right]}\end{array}$ & $\begin{array}{l}\mathrm{S}_{\mathrm{SAXS}}{ }^{j} \\
{\left[\mathrm{~m}^{2} / \mathrm{g}\right]}\end{array}$ & $\begin{array}{c}\mathrm{S}_{\mathrm{BET}} \\
{\left[\mathrm{m}^{2} / \mathrm{g}\right]}\end{array}$ \\
\hline DVB:TEVS $=1: 2$ & 45 & $\begin{array}{l}\text { 110(Spherical) } \\
45 \text { (Rod-type } \\
\text { cross-section) }\end{array}$ & 399 & 125 & 115 & 0.798 & 34.7 & 12.1 & 0.061 & 610 & 521 \\
\hline DVB:TEVS $=1: 1$ & 35 & 140 & 420 & 112 & 101 & 0.649 & 27.8 & 11.8 & 0.048 & 480 & 402 \\
\hline DVB:TEVS $=2: 1$ & 30 & 179 & 504 & 110 & 95 & 0.511 & 29.6 & 13.3 & 0.039 & 390 & 316 \\
\hline
\end{tabular}

${ }^{a}$ The volume-weighted particle size distribution $\mathrm{Dv}(\mathrm{R})$ as the maximum value of the function. ${ }^{\mathrm{b}}$ Pair distance distribution function PDDF as the maximum value of the function. ${ }^{c}$ Maximum dimension $D_{\max }$ means also $R$-value (distance) at which PDDF goes to 0 . This parameter is defined as diameter across the longest dimension of the particles and is zero for $r>D_{\max }{ }^{d}$ Radius of gyration as the mean square distance from the center of their distribution. $R_{g}$ provides a measure of the overall size of the scattering objects. ${ }^{e} R_{g}$ determined from $p(r)$ function is proportional to the normalized second moment of $p(r)$ (Equation.(4)) from the whole scattering curve. ${ }^{f}$ The Guinier plot, as $\ln (\mathrm{I}(\mathrm{q}))$ vs. $\mathrm{q}^{2}$ was used to determine the $\mathrm{R}_{\mathrm{g}}$ from the slope of the Guinier plot. ${ }^{\mathrm{g}}$ Porod constant is proportional to the surface area and the square of the electron density contrast. ${ }^{\mathrm{h}}$ Scattering invariant $\mathrm{Q}$ is proportional to the mean-square density fluctuation of scattering volume. $\mathrm{Q}=2 \pi^{2} \cdot \Delta \rho^{2} \cdot \mathrm{V}$ where volume $\mathrm{V}$ and scattering contrast $\Delta \rho$. For calculation $\mathrm{Q}$ invariant the scattering intensities to $\mathrm{q}=0$ and also towards large q should be extrapolated. ${ }^{i}$ Bacground constant which illustrates asymptotic decay of the SAXS curve at the high q values. ${ }^{j}$ Surface area by SAXS calculated by Equation (2).

Figure 3a shows logarithmic plots of the experimental scattering intensity I(q) as a function of the modulus of the scattering vector, $\mathrm{q}$, corresponding to organic-inorganic samples with different component fractions. The scattering curve is continuous and contains no pronounced extremes or peaks. The lack of a sharp interference peak on the SAXS profile suggests the absence of the regular superstructural forms of domains [47]. The experimental scattering curve includes the sum of the scattering of various phases and their interactions $[48,49]$. The nature of the scattering curve is similar for all studied samples. However, some differences in the level of scattering were observed. It was found that the introduction of the greater amount of TEVS into the polymeric body raises the intensity of scattering at low-angles.

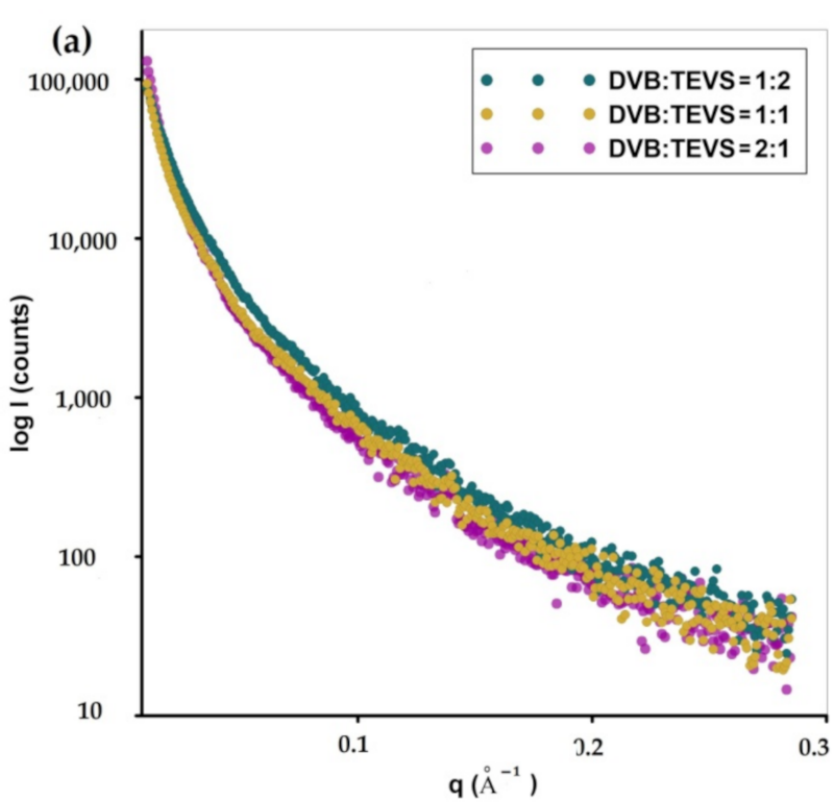

(b)

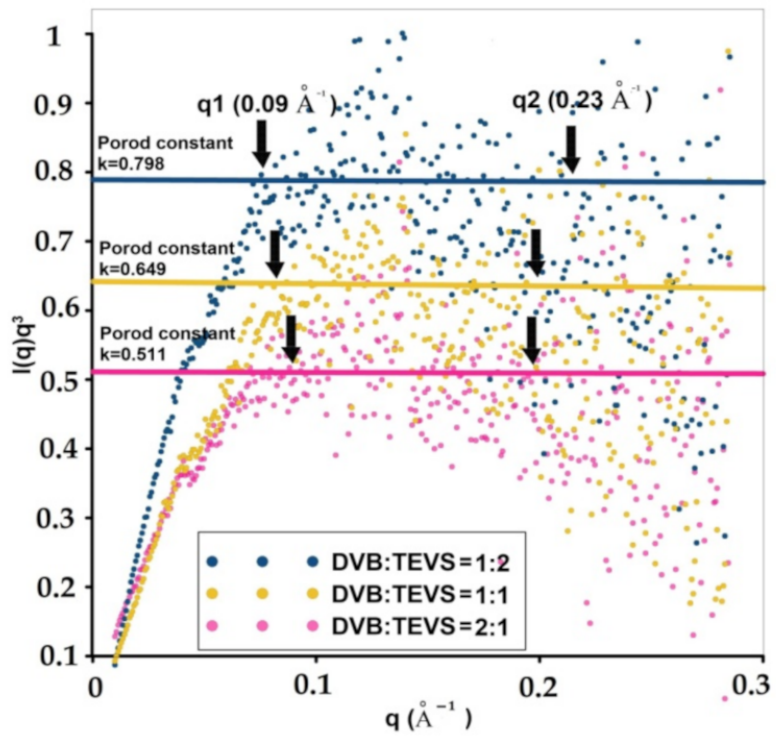

Figure 3. Cont. 


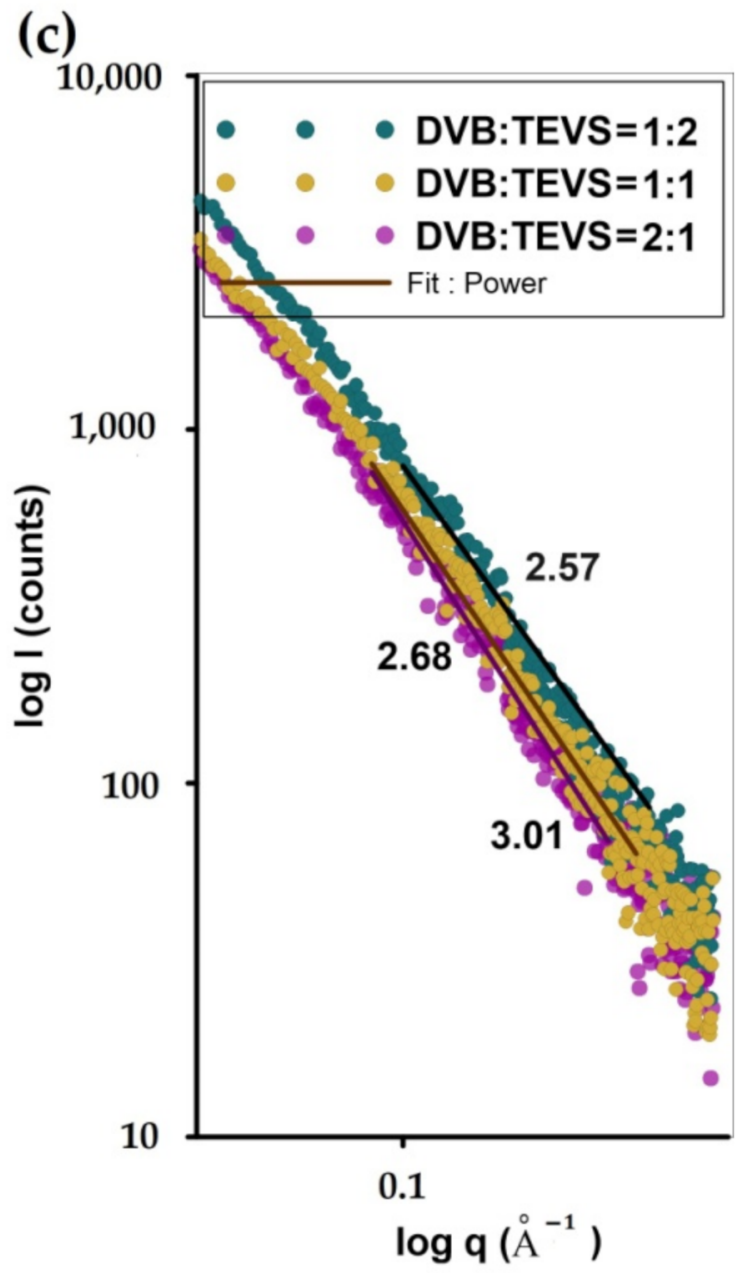

Figure 3. Experimental SAXS profiles corresponding to hybrid microspheres with various amounts of organic and inorganic components (a) Porod plots, and Porod constants determined from experimental patterns (b). The black arrows show the range of scattering vector suitable for the Porod linear range. The log-log plots of SAXS intensity in the power-law range (c).

The highest level of scattering was observed for DVB:TEVS $=1: 2$ sample, whereas the lowest was noticed for DVB:TEVS = 2:1. Due to the presence of scattering objects (polymer domains) in the materials' body, their size and relative quantity may be responsible for the scattering capacity and observed differences. Although all tested materials have a similar type of morphology, polymer domains in the DVB:TEVS $=1: 2$ sample should be marked as more visible. The phenomenon can be associated with the enhanced porosity of material as a result of greater amount of TEVS. In the case of this sample (DVB:TEVS $=1: 2$ ), increased porosity is associated with a higher amount of crosslinking agent and may cause the presence of additional nanometer forms (pores) able to generate the scattering effect $[50,51]$. In this way, a comparison of the level of scattering by hybrid samples can provide information about the degree of surface homogeneity [52,53].

The scattering properties of organic-inorganic materials can be discussed by Porod law. In this case, the scattering effect at large q values is applied. According to Porod law, the scattering curves of particle systems and porous materials with smooth surfaces decay proportionally to $\mathrm{q}^{-3}$ at large angles $\left(\mathrm{I}(\mathrm{q}) \approx \mathrm{k}_{3} / \mathrm{q}^{3}\right.$ for smeared data). When Porod's law is observed for experimental data (like in Figure $3 b$ ), it is a good indication of well-defined interfaces between regions of different electron density. Here, the scattered intensity is proportional to the reciprocal of suitable power of scattering vector $\left(\mathrm{I}(\mathrm{q}) \sim \mathrm{k}^{4}\right.$ for nonsmeared SAXS data and I(q) $\mathrm{k}^{3}$ for smeared SAXS data). Figure $3 \mathrm{~b}$ shows the calculated Porod plots for investigated samples. Porod curves display a plateau and the SAXS data asymptotically approaches a constant value. The procedure allows evaluating the Porod 
constant $\mathrm{k}$ based on the asymptotic decay of the scattering curve at the higher angles. The amplitude of the asymptote is proportional to the particle's surface-area-to-volume ratio and concentration. The most important feature of the Porod law suggests that the Porod constant is proportional to the surface area and the square of the electron density contrast. In this case, a simple comparison of the Porod constant allows illustrating the differences in the specific surface of materials in a way that is much simpler and faster than conventional methods of testing porosity. Comparing the absolute S/V values calculated from the Porod approximation, a clear decrease in the value for the sample containing the majority of the organic phase is visible. The $S / V$ values equal $0.061 \AA^{-1}, 0.048 \AA^{-1}$ and $0.039 \AA^{-1}$ for DVB:TEVS = 1:2, DVB:TEVS = 1:1, and DVB:TEVS = 2:1 samples, respectively. This suggests creating an extended three-dimensional surface of material containing mostly an inorganic blowing agent and a significant reduction of this surface by increasing the degree of smoothness using larger amounts of the organic phase. The estimated values of the

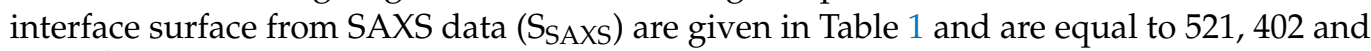
$311 \mathrm{~m}^{2} / \mathrm{g}$, respectively. Comparison of the specific surface area determined by using two different methods (low-temperature nitrogen sorption method: Brunauer-Emmett-Teller (BET) and SAXS indicates a correlation between both techniques for evaluating structural characteristics generated by polymer-domains and pores. Slight differences indicate a low amount of closed porosity of the microspheres.

Small-angle X-ray scattering allows conducting statistical analysis of scatters nanostructures. Figure 4a shows the volume-weighted particle (or pore) size distribution $\operatorname{Dv}(\mathrm{R})$ from the scattering curve of an ensemble of spherical particles (or pores) with homogeneous inner electron density distribution. Here, the size of the scattering objects can be determined. In this case, all nanometer objects are very similar (they have similar sizes). The difference concerns the relative number of these objects, which is reflected in the intensity of the maxima of $\operatorname{Dv}(\mathrm{R})$ curves. For the DVB:TEVS = 1:2 sample (Figure 4a) the size of most inhomogeneities is estimated to $40 \mathrm{~nm}$, however, a significant amount of these objects is in the range from $20 \mathrm{~nm}$ to $100 \mathrm{~nm}$. The size of scattering objects was significantly lower for DVB:TEVS = 1:1 and DVB:TEVS = 2:1 samples. Here the Dv $(R)$ function points to the significant number of objects with dimensions of $35 \mathrm{~nm}$ and 20-30 nm for DVB:TEVS $=1: 1$ and DVB:TEVS $=2: 1$, respectively. Moreover the radius of gyration as the mean square distance from the center of their distribution provides a measure of the overall size of the scattering objects. Here, the DVB:TEVS = 1:2 sample exhibit some cylinder geometry as cross-sectional dimension of the objects in comparison to typical spherical scatters. For DVB:TEVS = 1:1 and DVB:TEVS = 2:1 samples the fit of the PDDF function (pair distance distribution function) was satisfactory only for spherical systems (additional calculations were performed but not presented here). The roughness of the surface was evaluated by investigation of the Porod exponent (Figure 4c). The slope of a log-log plot of intensity vs. $q$ vector shows the fractal dimension of the scattering object. At high $q$ values, the $\mathrm{q}^{-3}$ function illustrates the smooth interfaces. The log-log plots of investigated samples shows the linear range of Porod range. The Porod exponent for scattering from materials is between 2 and 3 for a surface fractal in three-dimensional space. The obtained results suggest the smooth surface for DVB:TEVS = 2:1 microspheres. 

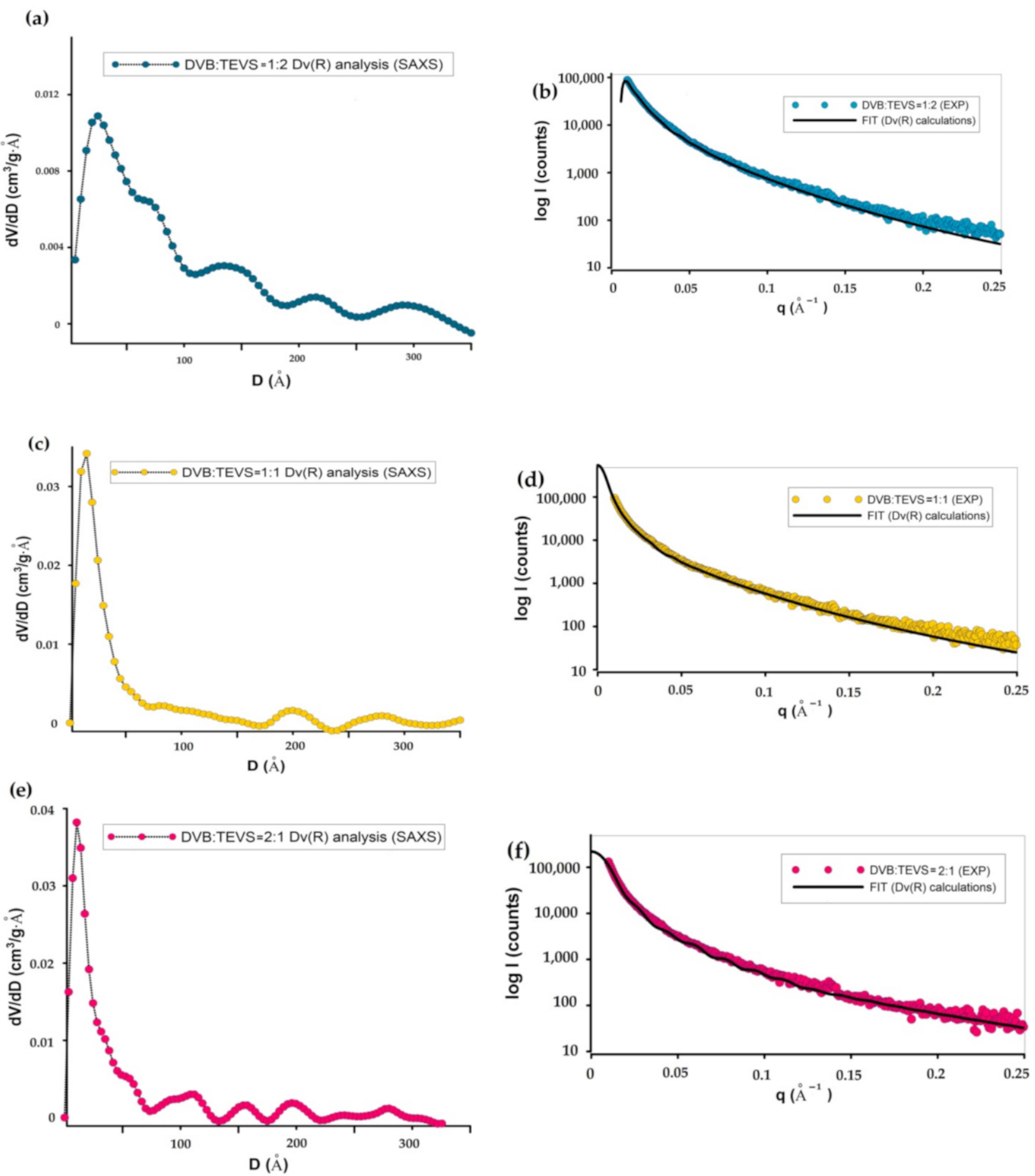

Figure 4. Particle Size Distribution by volume analysis Dv(R) for investigation systems: DVB:TEVS = 1:2 (a), DVB:TEVS = 1:1 (c) and DVB:TEVS = 2:1 (e). The insets of plots correspond to fit curves extrapolated for experimental SAXS data (b,d,f).

\subsubsection{Nitrogen Low-Temperature Sorption Analysis}

The porosity characteristics of polymeric-inorganic microspheres were determined on the basis of low-temperature nitrogen adsorption-desorption measurements. In Figures 5 and 6 the isotherms and pore size distributions are presented for all studied DVB-TEVS materials. The structure parameters are presented in Table 2. The differences in the isotherm course and nitrogen uptake reflect an essential variation of the porous structure. The shape of adsorption isotherms indicates a small content of micropores and significant content of mesopores. The difference between the adsorption and desorption is 
observed for all samples as elongated hysteresis loop of H1 type. The decrease of nitrogen adsorption, specific surface area and pore total volume is well correlated with DVB:TEVS ratio, more TEVS content the higher structure parameters. The highest specific surface areas $\left(\mathrm{S}_{\mathrm{BET}}\right)$ are for DVB:TEVS $=1: 2$, the medium for DVB:TEVS $=1: 1$ and the lowest for DVB:TEVS $=2: 1$ with values: $521,402,316 \mathrm{~m}^{2} / \mathrm{g}$, respectively. It is evident that the addition of crosslinking agent TEVS develops porous structure of organic-inorganic materials. The increase of pore size as the average value with increase of DVB content is observed, however, the differences are not significant. The pore size distribution functions for all studied materials show similar tendencies as those obtained from SAXS data. Generally, the determined values are in good agreement with data from SEM microscopy and SAXS analysis.

Table 2. The values of parameters characterizing the porous structure of DVB-TEVS.

\begin{tabular}{ccccccc}
\hline \multirow{2}{*}{ Sample } & \multicolumn{2}{c}{$\begin{array}{c}\text { Surface Area }\left(\mathbf{S}_{\mathrm{BET}}\right) \\
{\left[\mathbf{m}^{2} / \mathbf{g}\right]}\end{array}$} & \multicolumn{2}{c}{$\begin{array}{c}\text { Pore Volume } \\
{\left[\mathbf{c m}^{3} / \mathbf{g}\right]}\end{array}$} & \multicolumn{2}{c}{$\begin{array}{c}\text { Pore Size } \\
{[\mathbf{n m}]}\end{array}$} \\
\cline { 2 - 7 } & $\mathbf{S}_{\text {BETTotal }}{ }^{\mathbf{2}}$ & $\mathbf{S}_{\text {MIC }}{ }^{\mathbf{b}}$ & $\mathbf{V}_{\text {Total }}{ }^{\mathbf{c}}$ & $\mathbf{V}_{\text {MIC }}{ }^{\mathbf{d}}$ & $\mathbf{D}_{\mathbf{h}}{ }^{\mathbf{e}}$ & $\mathbf{B J H}_{\text {ADS }}{ }^{\mathbf{f}}$ \\
\hline DVB:TEVS = 1:2 & 521 & - & 0.84 & - & 6.4 & 4.8 \\
DVB:TEVS = 1:1 & 402 & 2.5 & 0.74 & - & 7.4 & 5.1 \\
DVB:TEVS = 2:1 & 316 & 27 & 0.54 & 0.01 & 6.8 & 5.8 \\
\hline
\end{tabular}

${ }^{a} S_{B E T}$, the BET specific surface area; ${ }^{b} S_{M I C}$, the micropore surface area; ${ }^{c} V_{t}$, the total pore volume; ${ }^{d} V_{M I C}$, the micropore volume; ${ }^{e} D_{h}$, the average hydraulic pore diameter $(4 \mathrm{~V} / \mathrm{A}) ;{ }^{\mathrm{f}} \mathrm{BJ} \mathrm{H}_{\mathrm{ADS}}$, average $\mathrm{BJH}$ adsorption pore diameter.

(a)

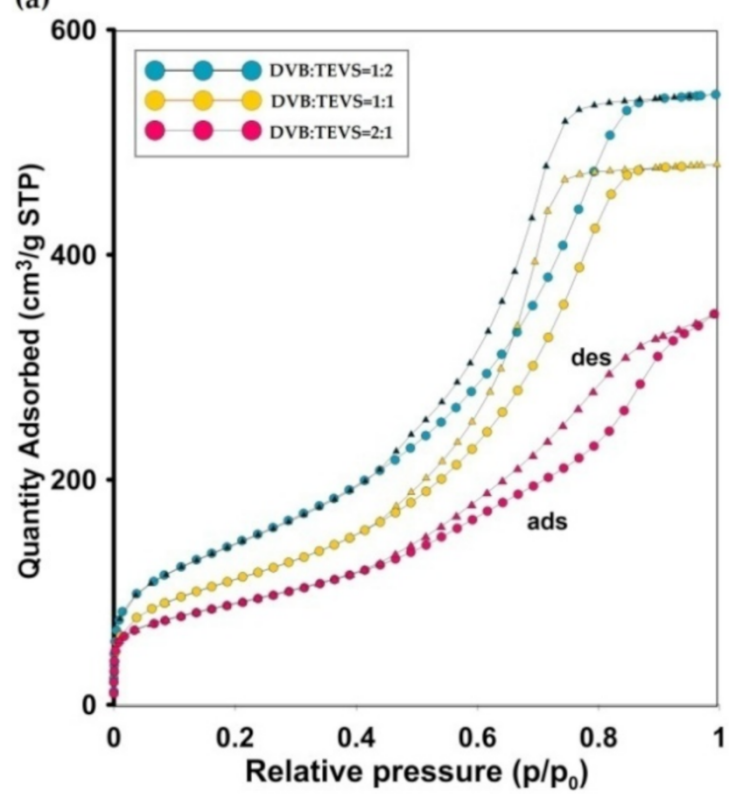

(b)

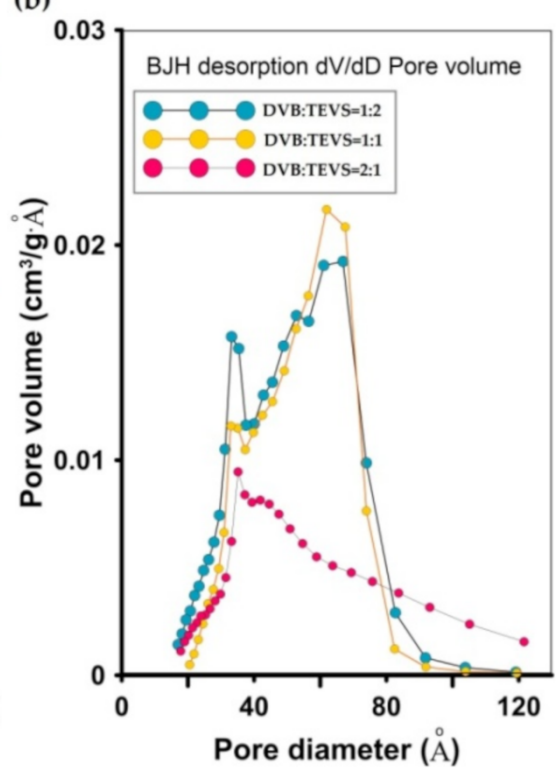

Figure 5. Cont. 
(c)

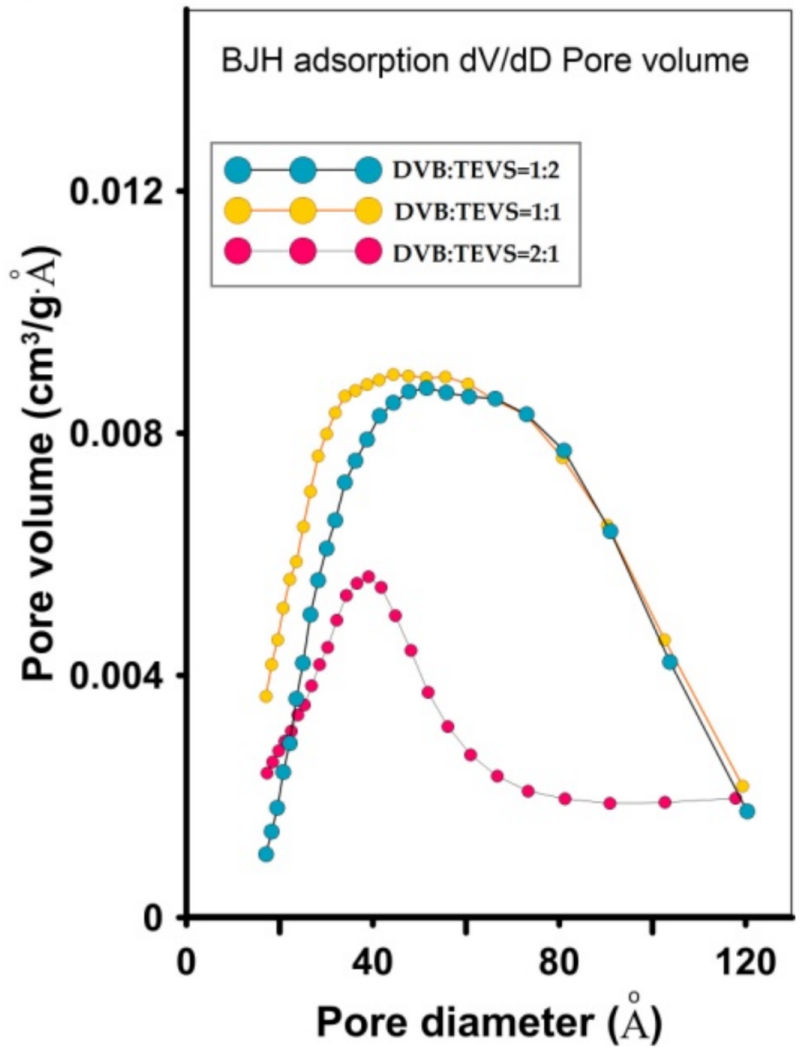

Figure 5. The nitrogen adsorption-desorption isotherms for DVB-TEVS materials (a), pore size distributions by the BarrettJoyner-Halenda (BJH) with Halsey-Faas correction for desorption (b) and adsorption data (c).

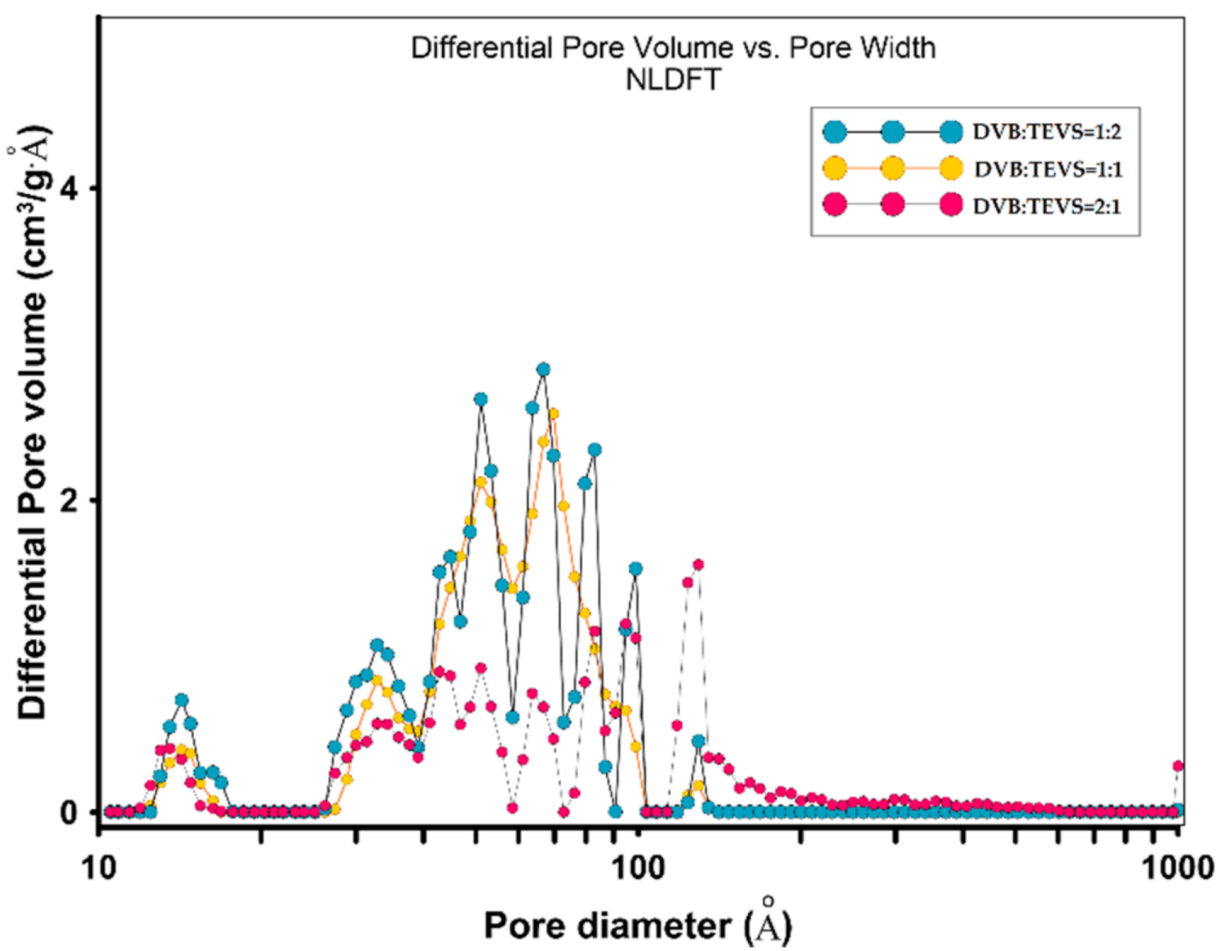

Figure 6. Pore size distributions obtained by Density Functional Theory with Model: N2 @ 77 K, Slit Pores. Method: Non-negative Regularization: 0.01000 and Standard Deviation of Fit: $6.62419 \mathrm{~cm}^{3} / \mathrm{g}$ STP. 


\subsection{Adsorption Studies}

In order to investigate the adsorption effectiveness of the synthesized microspheres the kinetic profiles for nitrobenzene (NB), 4-nitrophenol (4-NP) and phenol (P) adsorption from aqueous solutions were measured. In Figure 7, Figure 8 and Figure S2 (Supplementary Material) the concentration and adsorption profiles on DVB:TEVS $=2: 1$, DVB:TEVS $=1: 2$ and DVB:TEVS $=1: 1$ materials are compared.
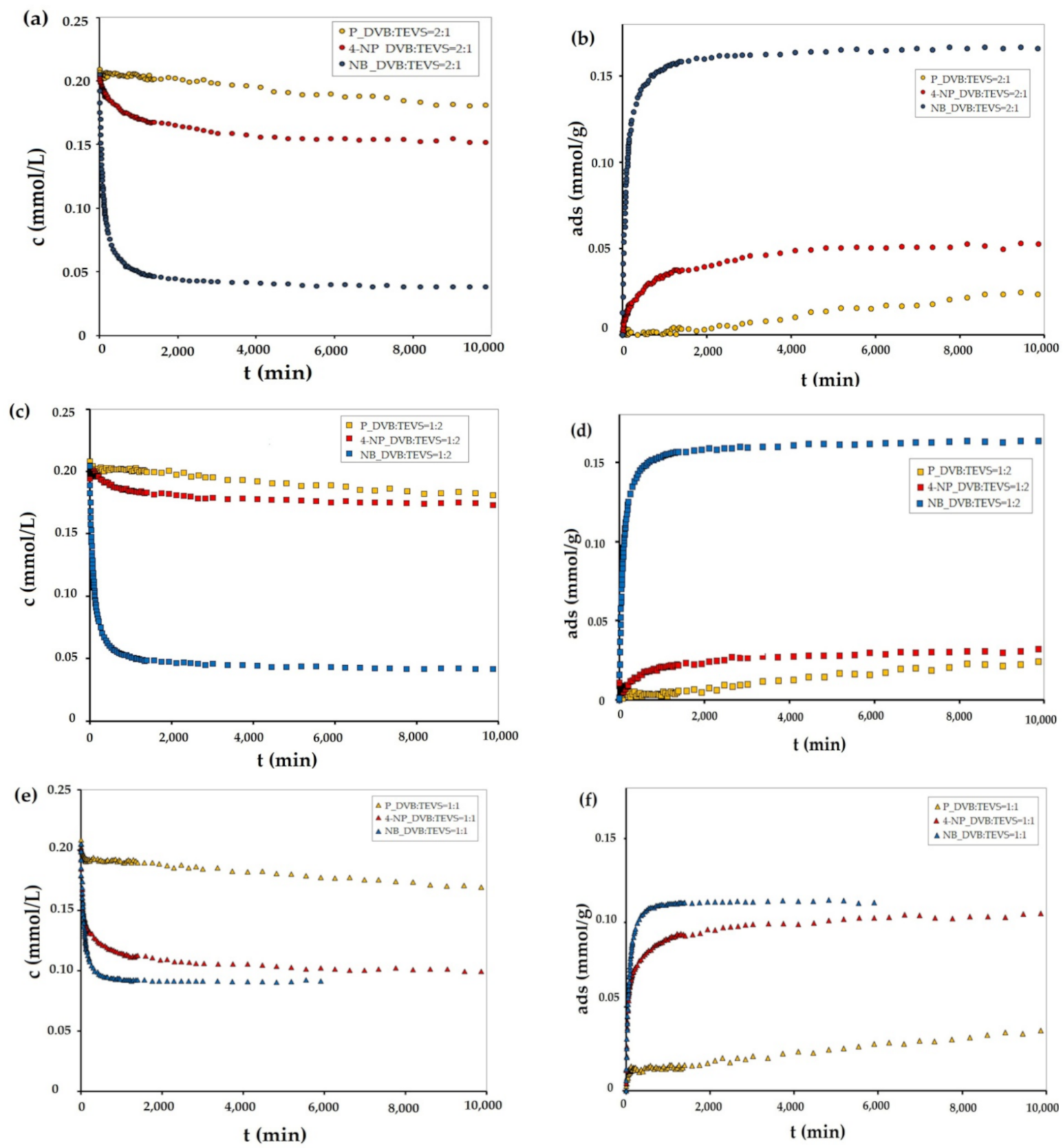

Figure 7. Adsorption kinetics for NB, P and 4-NP on DVB:TEVS = 2:1 (a,b), DVB:TEVS = 1:2 (c,d) and DVB:TEVS:1:1 (e,f) microspheres presented as changes in concentration over time and changes in adsorption over time. 

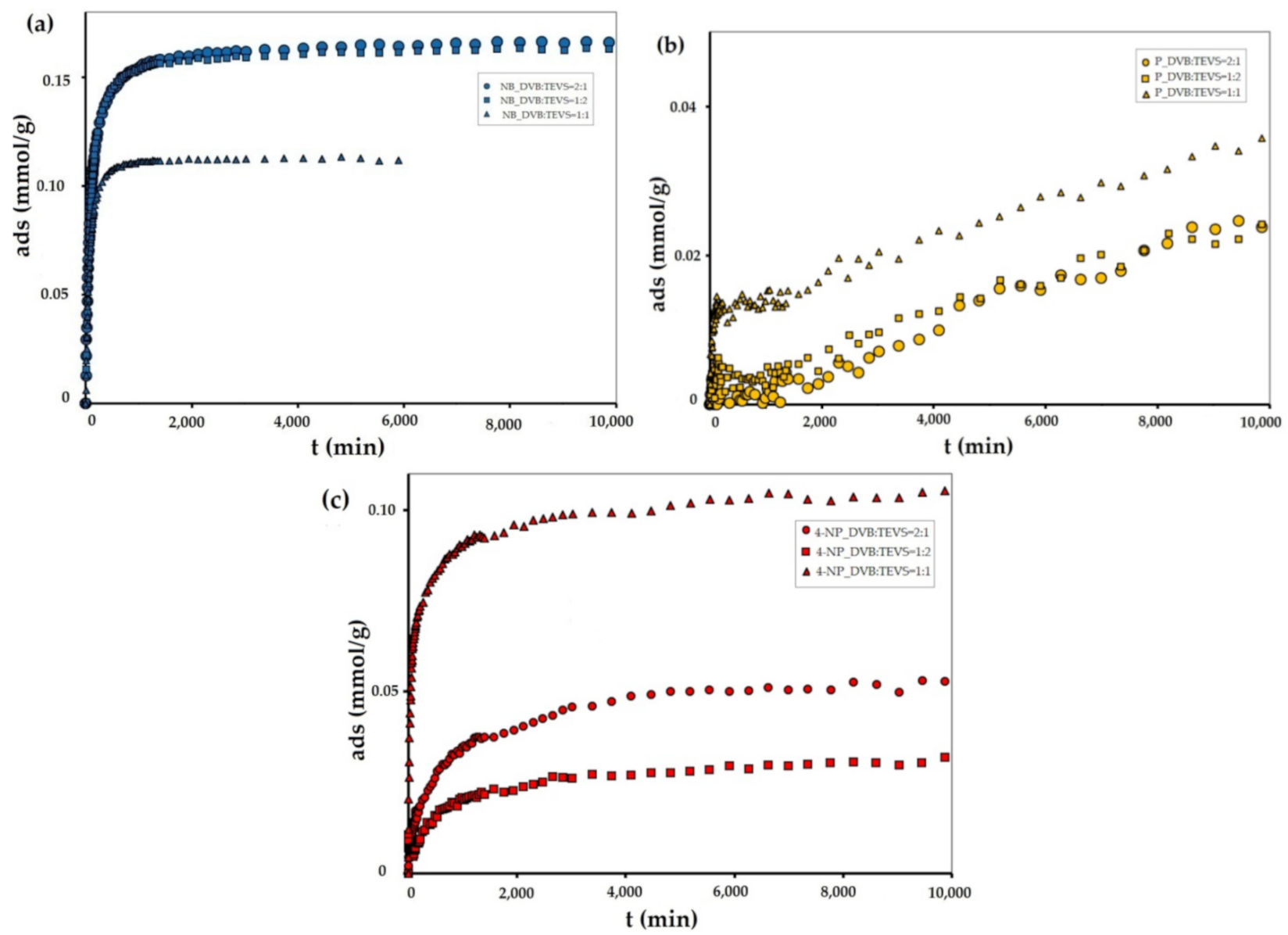

Figure 8. Adsorption kinetics for NB (a), P (b) and 4-NP (c) on DVB:TEVS = 2:1, DVB:TEVS = 1:2 and DVB:TEVS = 1:1 materials presented as changes in adsorption over time.

Let us first discuss the differentiation of adsorbate affinity to a given material. Based on the analysis of kinetic data presented in Figure 7, one can find that for all tested materials the strongest decrease of adsorbate concentration is observed for nitrobenzene, and the lowest for phenol. This effect can be explained based on the differences in solute solubility, whereby compounds with a lower solubility in water generally have a greater affinity to the hydrophobic surface of the adsorbent [33]. Next one can discuss the differentiation of the adsorption properties of all DVB-TEVS materials towards various solutes. Basing on the analysis of data presented in Figure 8 and Figure S2, we can find the differences in the amount and rate of concentration loss from the solution of nitrobenzene, phenol and 4-nitrophenol. In the case of nitrobenzene adsorption (Figure 8a and Figure S2a), the greatest adsorbate losses from the solution are noted for the experimental system with the most hydrophobic DVB:TEVS $=2: 1$, slightly smaller for the least hydrophobic DVB:TEVS $=1: 2$, and the smallest for DVB:TEVS $=1: 1$ with intermediate properties. In the case of 4-nitrophenol and phenol adsorption the greatest adsorbate losses are observed for DVB:TEVS = 1:1. Comparing the adsorption effectiveness of the obtained materials towards different adsorbates one can find a relatively large degree of similarity between the DVB:TEVS $=2: 1$ and DVB:TEVS $=1: 2$, however, DVB:TEVS $=1: 1$ shows quite different properties. Such a differentiated behaviour may be explained taking into account not only the hydrophobic/hydrophilic properties, but also the structural adsorbent characteristics and polymer swelling which can be responsible for penetration of adsorbate molecules into the material structure. As it will be discussed later basedon the thermal analysis data, the interactions of solute molecules with DVB-TEVS microspheres have physical character. Thus, the measured kinetic profiles reveal the global effect of all these factors. 
The obtained experimental data were analysed using many equations and adsorption kinetics models. The relative standard deviations obtained in fitting procedure are listed in Table 3. It was observed that the best quality of fitting to the kinetic data was obtained for a multi-exponential equation, which parameters are summarized in Table 6. As can be seen, adsorption in the investigated experimental systems is a complex process, which kinetics can be described by two or three terms of the m-exp equation. The fitting quality is very good, which is confirmed by low values of relative standard deviations $S D(c) / c_{o}$ in the range from $0.205 \%$ to $0.805 \%$ and low values of determination factors $1-R^{2}$ in the range from $4.2 \times 10^{-4}$ to $5.4 \times 10^{-2}$. Additionally, the $u_{e q}$ parameter values confirm the differences in the adsorption values. Moreover, for all tested systems, the half time $t_{1 / 2}$ values are determined, which are defined as the time needed to obtain a half of the concentration change. The obtained half-time values confirm the differences in the adsorption rates of NB, $\mathrm{P}$ and 4-NP. Additionally, based on the analysis of the data presented in Figure 7, Figure 8 and Figure S2, and in Table 4 it may be found that the highest adsorption kinetics for all tested adsorbates was recorded in the system with the DVB:TEVS $=1: 1$.

Summing up the discussion on DVB-TEVS adsorption effectiveness one can find that the synthesized materials show remarkable selectivity towards various adsorbates. Depending on the synthesis procedure it is possible to obtain the materials which are characterized by divergent uptakes and kinetic characteristics.

Table 3. Relative standard deviations SD(c)/co (\%) for m-exp, FOE, SOE, MOE, f-FOE, f-SOE, F-MOE, McKay pore diffusion (PDM) and IDM model (Crank).

\begin{tabular}{cccccccccc}
\hline System & $\begin{array}{c}\text { m-exp } \\
\mathbf{( \% )}\end{array}$ & $\begin{array}{c}\text { FOE } \\
\mathbf{( \% )}\end{array}$ & $\begin{array}{c}\text { SOE } \\
\mathbf{( \% )}\end{array}$ & $\begin{array}{c}\text { MOE } \\
\mathbf{( \% )}\end{array}$ & $\begin{array}{c}\text { f-FOE } \\
\mathbf{( \% )}\end{array}$ & $\begin{array}{c}\text { f-SOE } \\
\mathbf{( \% )}\end{array}$ & $\begin{array}{c}\text { f-MOE } \\
\mathbf{( \% )}\end{array}$ & $\begin{array}{c}\text { IDM } \\
\mathbf{( \% )}\end{array}$ & $\begin{array}{c}\text { PDM } \\
\mathbf{( \% )}\end{array}$ \\
\hline NB/DVB:TEVS = 2:1 & 0.544 & 3.200 & 0.703 & 0.935 & 1.281 & 0.635 & 0.651 & 5.81 & 24.78 \\
NB/DVB:TEVS = 1:2 & 0.469 & 2.480 & 0.695 & 0.699 & 1.310 & 0.498 & 0.501 & 7.21 & 25.92 \\
NB/DVB:TEVS = 1:1 & 0.205 & 1.227 & 0.995 & 0.999 & 0.473 & 0.581 & 0.395 & 15.36 & 24.75 \\
P/DVB:TEVS = 2:1 & 0.805 & 0.802 & 0.818 & 0.794 & 0.685 & 0.680 & 0.684 & 10.36 & 23.89 \\
P/DVB:TEVS = 1:2 & 0.704 & 0.776 & 0.782 & 0.772 & 0.763 & 0.750 & 0.711 & 9.06 & 22.56 \\
P/DVB:TEVS = 1:1 & 0.506 & 1.455 & 1.450 & 1.459 & 1.330 & 1.351 & 1.351 & 6.87 & 18.96 \\
4-NP/DVB:TEVS = 2:1 & 0.397 & 1.277 & 0.791 & 0.796 & 0.407 & 0.427 & 0.408 & 8.78 & 29.56 \\
4-NP/ DVB:TEVS = 1:2 & 0.572 & 0.801 & 0.704 & 0.708 & 0.750 & 0.704 & 0.709 & 9.64 & 28.25 \\
4-NP/DVB:TEVS = 1:1 & 0.669 & 3.519 & 4.949 & 1.889 & 1.737 & 0.999 & 9.694 & 13.53 & 21.64 \\
\hline
\end{tabular}

Table 4. Optimized parameters of m-exp equation.

\begin{tabular}{|c|c|c|c|c|c|c|c|}
\hline System & $f_{1}, \log k_{1}$ & $f_{2}, \log k_{2}$ & $f_{3}, \log k_{3}$ & $u_{e q}$ & $\begin{array}{c}t_{1 / 2} \\
(\mathrm{~min})\end{array}$ & $\begin{array}{c}S D(c) / c_{0} \\
(\%)\end{array}$ & $1-R^{2}$ \\
\hline NB/DVB:TEVS $=2: 1$ & $0.095,0.116$ & $0.627,-1.90$ & $0.278,-2.81$ & 0.805 & 73.1 & 0.544 & $5.2 \cdot 10^{-4}$ \\
\hline NB/DVB:TEVS $=1: 2$ & $0.080,-0.967$ & $0.715,-1.968$ & $0.205,-2.851$ & 0.788 & 75.9 & 0.469 & $9.6 \cdot 10^{-4}$ \\
\hline NB/DVB:TEVS = 1:1 & $0.056,0.187$ & $0.686,-1.809$ & $0.258,-2.451$ & 0.553 & 55.9 & 0.205 & $4.2 \cdot 10^{-4}$ \\
\hline P/DVB:TEVS = 2:1 & $0.005,-0.788$ & $0.995,-4.881$ & - & 0.148 & 52334.6 & 0.805 & $5.4 \cdot 10^{-2}$ \\
\hline $\mathrm{P} / \mathrm{DVB}:$ TEVS $=1: 2$ & $0.018,-0.889$ & $0.982,-4.939$ & - & 0.154 & 52334.6 & 0.704 & $5.1 \cdot 10^{-2}$ \\
\hline P/DVB:TEVS = 1:1 & $0.056,-1.452$ & $0.006,-0.816$ & $0.938,-4.870$ & 0.168 & 46568.7 & 0.506 & $1.6 \cdot 10^{-2}$ \\
\hline 4-NP/DVB:TEVS = 2:1 & $0.124,-1.332$ & $0.368,-2.518$ & $0.508,-3.380$ & 0.256 & 483.9 & 0.397 & $2.3 \cdot 10^{-3}$ \\
\hline 4-NP/DVB:TEVS = 1:2 & $0.130,1.063$ & $0.450,-2.839$ & $0.370,-4.040$ & 0.180 & 803.6 & 0.572 & $1.4 \cdot 10^{-2}$ \\
\hline 4-NP/DVB:TEVS = 1:1 & $0.049,-0.071$ & $0.598,-1.607$ & $0.353,-2.972$ & 0.499 & 51.8 & 0.669 & $2.4 \cdot 10^{-3}$ \\
\hline
\end{tabular}

\subsection{Thermal Analysis}

Thermal analysis is a very useful technique for the characterization of materials, which may be also helpful in investigations of adsorbate-adsorbent interactions. The thermal properties of pure polymer-silane hybrids and the materials loaded with organic adsorbates were investigated using TG, DTG and DSC techniques. In Figure 9, the TG, DTG and DSC curves measured for the synthesized DVB-TEVS materials are presented. One can state that 
they show similar thermal behaviour with several stages of the thermal degradation. The data obtained from TG/DTG/DSC curves are summarized in Table 5. The thermal analysis proved that up to $170{ }^{\circ} \mathrm{C}$ the materials are highly thermally stable. The exothermic peaks visible on DSC curve starting at $170{ }^{\circ} \mathrm{C}$ may be associated with the additional crosslinking processes related to the presence of tetrafunctional DVB monomer. The main step related to thermal destruction of crosslinked microspheres follows at temperatures $330-550{ }^{\circ} \mathrm{C}$ with the maximum at about $450{ }^{\circ} \mathrm{C}$. In this stage an $84-85 \%$ decrease in the weight of studied materials is observed. In the $550-950{ }^{\circ} \mathrm{C}$ temperature range the weight loss is below 3\%. The total mass loss is similar for all DVB-TEVS materials and it is about $87 \%$. These results confirm that the materials are thermally stable up to at least $330^{\circ} \mathrm{C}$ and the main destruction process occurs at about $450{ }^{\circ} \mathrm{C}$, therefore, the synthesized materials may be applied in relatively wide temperature ranges. These observations were confirmed with the data of identification of thermal destruction products by mass spectrometry (MS) analysis. The MS profiles for DVB:TEVS = 1:1 are shown in Figures 10 and 11. The MS analysis confirms that the initial decomposition of these materials happens below $200{ }^{\circ} \mathrm{C}$, and the major material destruction process is above $330^{\circ} \mathrm{C}$. Moreover, the MS data indicate that the thermal behaviour of DVB-TEVS materials is strictly connected with the presence of the 1,4-divinylbenzene matrix. The course of TG, DTG and DSC curves as well as MS spectra for the DVB:TEVS materials (Figures 9 and 10) and pure DVB (presented in Figures S3-S5, (Supplementary Material)) are similar. Many signals from the defragmentation of the aromatic structure of divinylbenzene are visible: water $(m / z=18)$, vinyl group $(m / z=27)$, ethyl group $(m / z=29)$, benzene $(m / z=78)$, phenyl group $(m / z=77)$, benzyl group $(m / z=91)$. In addition, the gaseous MS profiles of thermal degradation of the studied materials confirm the presence of triethoxyvinylsilane coupling agent (Figure S6 for DVB:TEVS = 1:1, Supplementary Material) $(m / z=189)$ and absence of TEVS in pure polymer.
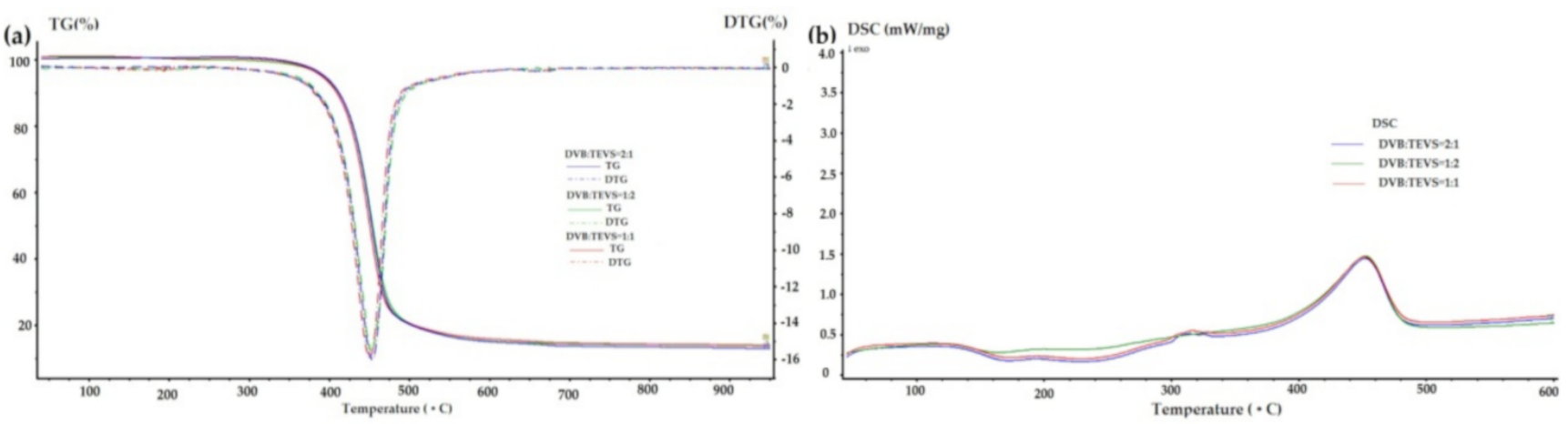

Figure 9. TG, DTG (a) and DSC (b) curves for DVB-TEVS materials measured in helium conditions.

Table 5. TG, DTG and DSC data obtained in helium atmosphere for DVB-TEVS materials.

\begin{tabular}{|c|c|c|c|c|c|c|c|}
\hline \multirow[b]{2}{*}{ Sample } & \multicolumn{4}{|c|}{ TG [\%] } & \multirow{2}{*}{$\frac{\mathrm{DTG}}{\mathrm{T}_{\mathrm{d}}\left[{ }^{\circ} \mathrm{C}\right]}$} & \multicolumn{2}{|c|}{ DSC } \\
\hline & $\begin{array}{c}\mathrm{m}_{\mathrm{IDT}} \\
\left(170-330{ }^{\circ} \mathrm{C}\right)\end{array}$ & $\begin{array}{c}\mathrm{m}_{\text {loss }} \\
\mathbf{3 3 0 - 5 5 0}{ }^{\circ} \mathrm{C}\end{array}$ & $\begin{array}{c}\mathrm{m}_{\text {loss }} \\
550-950{ }^{\circ} \mathrm{C}\end{array}$ & $\begin{array}{c}\mathbf{m}_{\text {loss }} \\
\text { TOTAL }\end{array}$ & & $\mathrm{T}_{\mathrm{d}}\left[{ }^{\circ} \mathrm{C}\right]$ & $\Delta \mathbf{H}_{\mathrm{d}}[\mathrm{J} / \mathrm{g}]$ \\
\hline DVB:TEVS $=1: 2$ & 1.39 & 83.99 & 1.47 & 86.85 & 453 & 453 & 150.8 \\
\hline DVB:TEVS = 1:1 & 0.92 & 83.87 & 1.89 & 86.68 & 450 & 453 & 145.7 \\
\hline DVB:TEVS = 2:1 & 0.36 & 85.06 & 2.13 & 87.55 & 453 & 453 & 147.4 \\
\hline
\end{tabular}




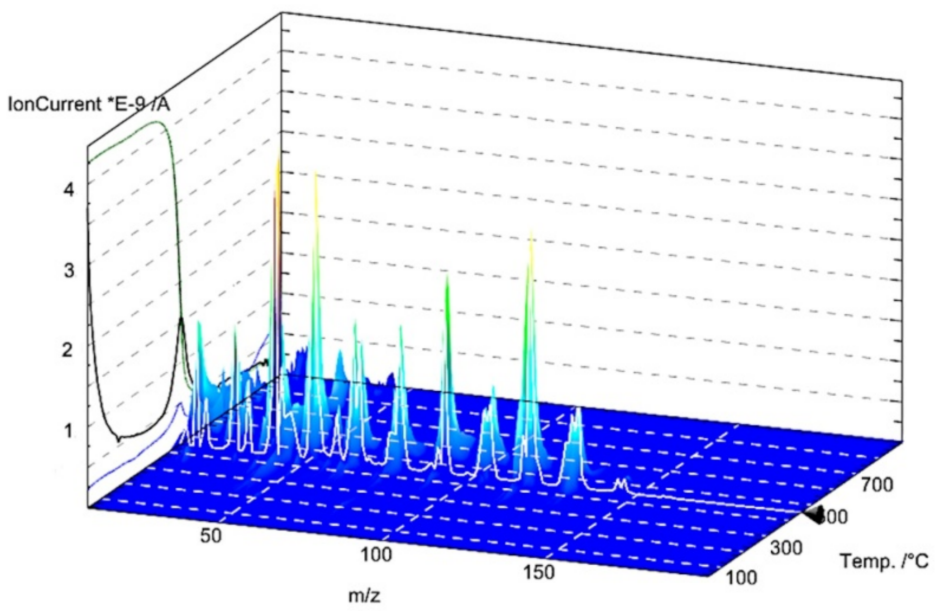

Figure 10. 3D MS profile registered during decomposition of pure DVB:TEVS = 1:1.
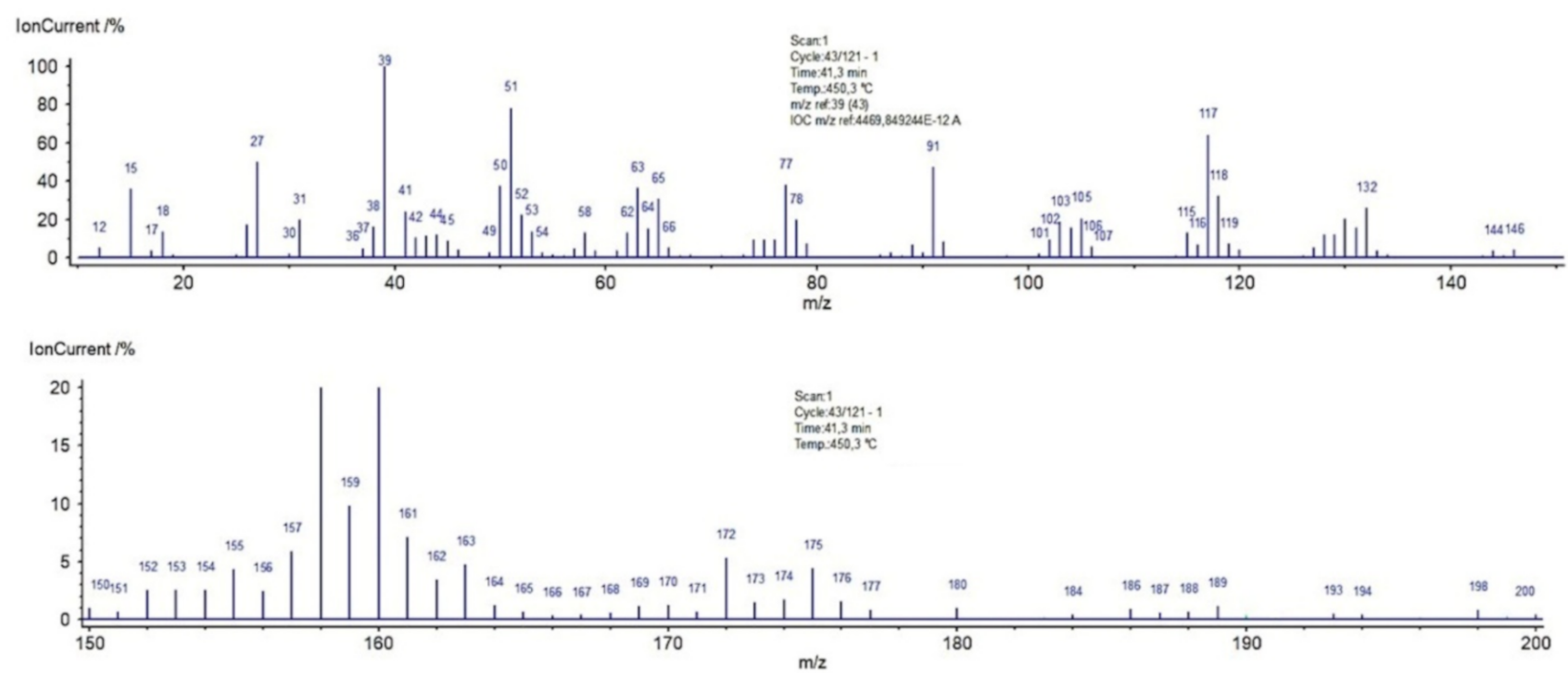

Figure 11. MS spectra of DVB:TEVS $=1: 1$ decomposition at $450{ }^{\circ} \mathrm{C}$.

Taking into consideration the TG, DTG and DSC curves obtained for the materials loaded with organic solutes (Figure 12, Figure 13, Figure 14 and Table 6) one can find small differences for various adsorbates. In the range of $170-330{ }^{\circ} \mathrm{C}$ the weight losses for all materials with adsorbed organic solutes are higher than in the case of pure DVBTEVS materials (0.4-1.4\%) suggesting relatively weak adsorbent-adsorbate interactions of physical nature. However, for 4-NP and P the weight loss is higher (2.6-4\%) in comparison to the NB (0.7-1.3\%)-containing sample. 

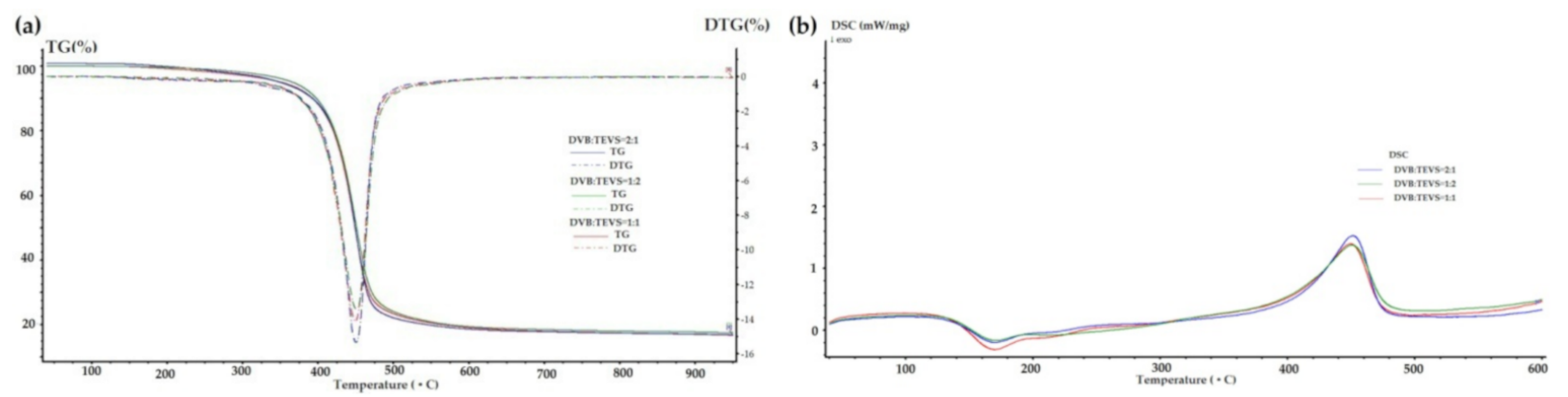

Figure 12. TG, DTG (a) and DSC (b) curves for DVB-TEVS materials measured in helium conditions after adsorption of P.
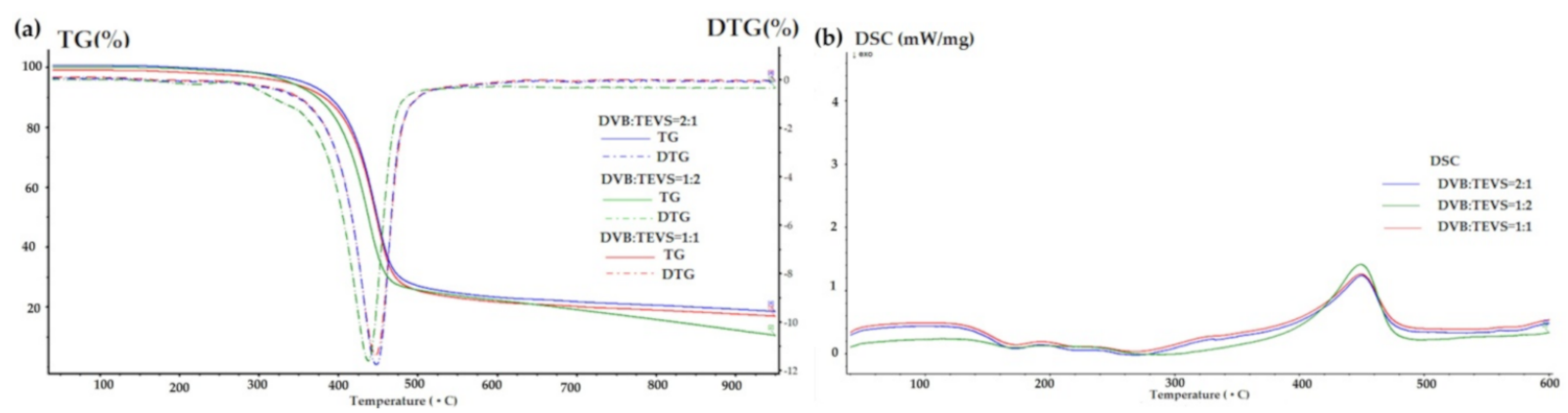

Figure 13. TG, DTG (a) and DSC (b) curves for DVB-TEVS materials measured in helium conditions after adsorption of 4-NP.
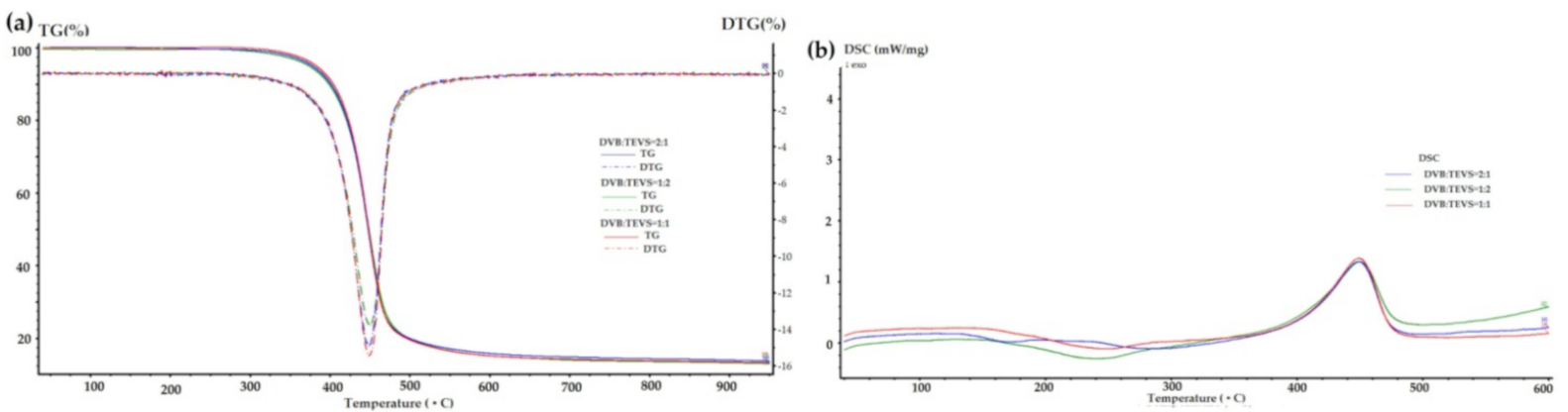

Figure 14. TG, DTG (a) and DSC (b) curves for DVB-TEVS materials measured in helium conditions after adsorption of NB.

Table 6. TG, DTG and DSC data obtained in helium atmosphere for DVB-TEVS materials with loaded P, 4-NP and NB.

\begin{tabular}{|c|c|c|c|c|c|c|c|}
\hline \multirow{2}{*}{ Sample } & \multicolumn{4}{|c|}{ TG [\%] } & \multirow{2}{*}{$\frac{\text { DTG }}{\mathrm{T}_{\mathrm{d}}\left[{ }^{\circ} \mathrm{C}\right]}$} & \multicolumn{2}{|c|}{ DSC } \\
\hline & $\frac{\mathrm{m}_{\mathrm{IDT}}}{\left(170-330{ }^{\circ} \mathrm{C}\right)}$ & 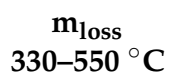 & $\underset{550-950{ }^{\circ} \mathrm{C}}{\mathrm{m}_{\text {loss }}}$ & $\begin{array}{c}\mathrm{m}_{\text {loss }} \\
\text { TOTAL }\end{array}$ & & $\mathbf{T}_{\mathbf{d}}\left[{ }^{\circ} \mathbf{C}\right]$ & $\Delta \mathbf{H}_{\mathrm{d}}[\mathrm{J} / \mathrm{g}]$ \\
\hline P_DVB:TEVS = 1:2 & 2.61 & 75.69 & 3.11 & 81.41 & 450 & 452 & 164.8 \\
\hline P_DVB:TEVS $=1: 1$ & 3.41 & 75.86 & 3.60 & 82.87 & 450 & 452 & 167.1 \\
\hline P_DVB:TEVS $=2: 1$ & 3.98 & 76.76 & 2.73 & 83.47 & 450 & 452 & 198.2 \\
\hline NP_DVB:TEVS $=1: 2$ & 3.70 & 72.62 & 8.50 & 84.82 & 440 & 449 & 191.1 \\
\hline NP_DVB:TEVS $=1: 1$ & 3.19 & 72.51 & 6.02 & 81.72 & 449 & 449 & 134.5 \\
\hline NP_DVB:TEVS $=2: 1$ & 3.25 & 72.53 & 5.96 & 81.74 & 449 & 449 & 135.8 \\
\hline NB_DVB:TEVS $=1: 2$ & 1.24 & 80.20 & 2.97 & 84.41 & 450 & 450 & 170.2 \\
\hline NB_DVB:TEVS $=1: 1$ & 0.67 & 83.25 & 2.67 & 86.59 & 449 & 450 & 199.5 \\
\hline NB_DVB:TEVS $=2: 1$ & 1.29 & 81.61 & 2.90 & 85.80 & 448 & 450 & 186.9 \\
\hline
\end{tabular}

The TG, DTG and DSC results were completed by mass spectrometry analysis. The 3D MS profiles and MS spectra for DVB:TEVS = 1:1 with adsorbed organic substances are presented in Figures 15 and 16. The gaseous MS profiles of DVB-TEVS materials af- 
ter adsorption (Figure 17) revealed that in the case of 4-NP certain amounts of nitrogen compounds released above $170{ }^{\circ} \mathrm{C}$ are found: nitrogen oxide $(\mathrm{m} / \mathrm{z}=30)$, nitrogen dioxide $(\mathrm{m} / \mathrm{z}=46)$ and also small amounts of nitrophenol $(\mathrm{m} / \mathrm{z}=139)$ and nitrobenzene $(\mathrm{m} / \mathrm{z}=123)$. These products of thermal decomposition confirm the adsorption 4-NP and explain the higher mass losses in the range of $170-330^{\circ} \mathrm{C}$. In the case of NB adsorption larger amounts of nitrogen compounds evaporate up to $100^{\circ} \mathrm{C}$ (the MS signals recorded at low temperatures), thus, it explains lower mass losses in the range $170-330^{\circ} \mathrm{C}$ in comparison to 4-NP. The main step of the destruction of microspherical structures with residues of adsorbates occurs runs at a maximum of $450{ }^{\circ} \mathrm{C}$.

(a)

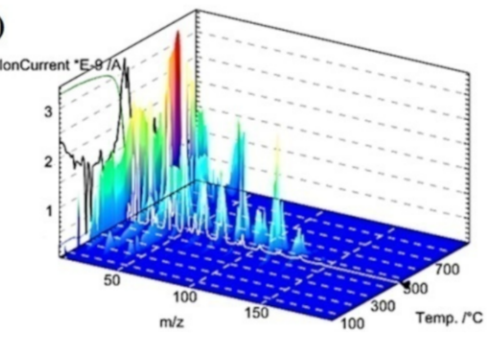

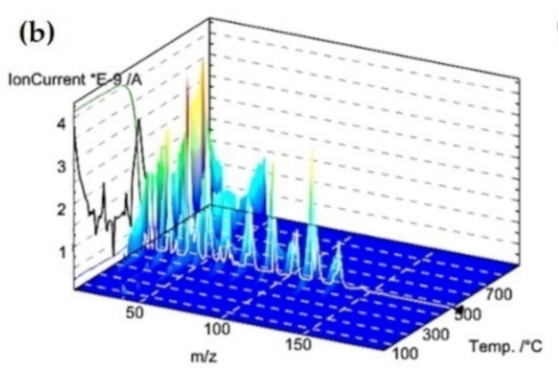

(c)

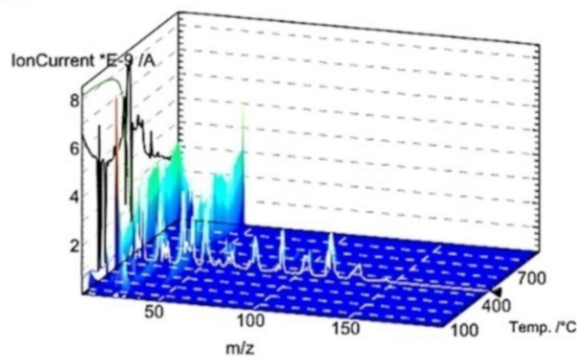

Figure 15. 3D MS profiles registered during decomposition of DVB:TEVS = 1:1 after adsorption of $\mathrm{P}(\mathbf{a}), 4-\mathrm{NP}(\mathbf{b})$ and NB (c).

(a)

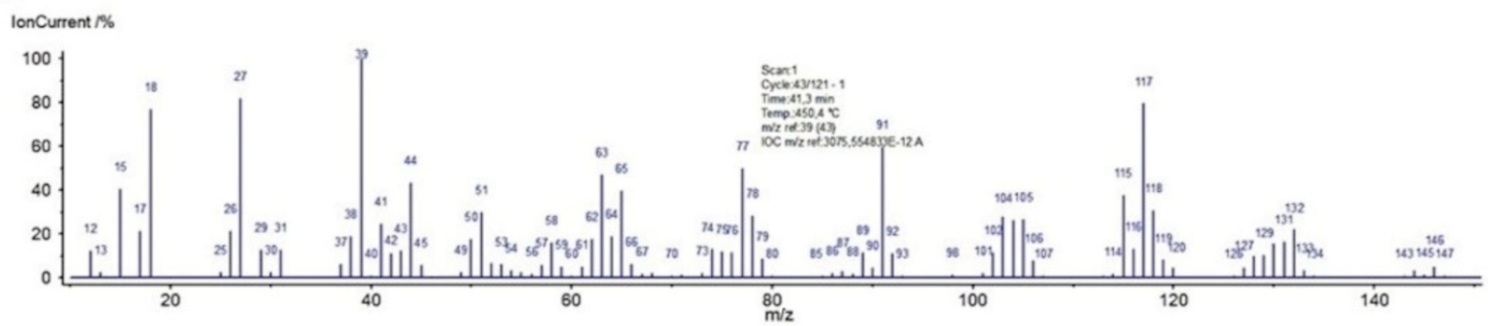

(b)

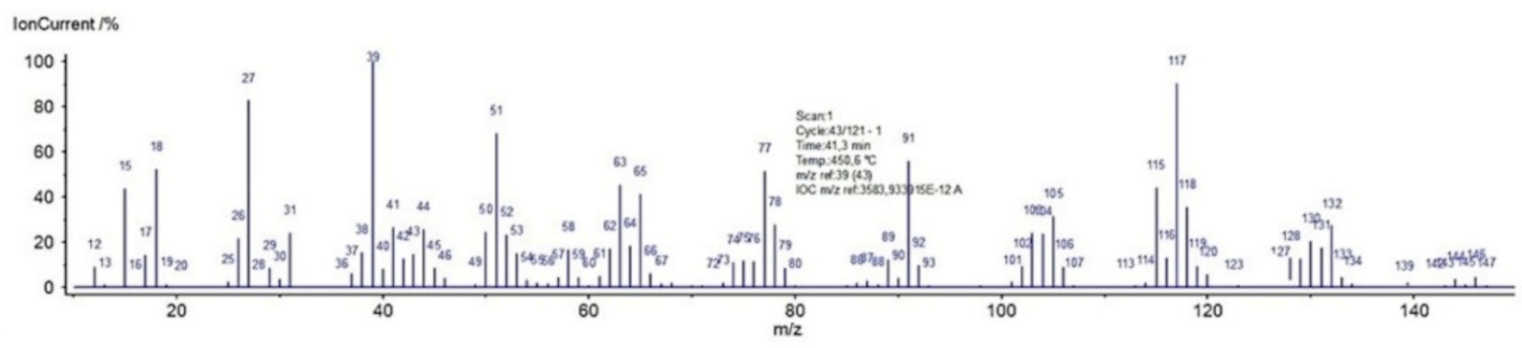

(c)

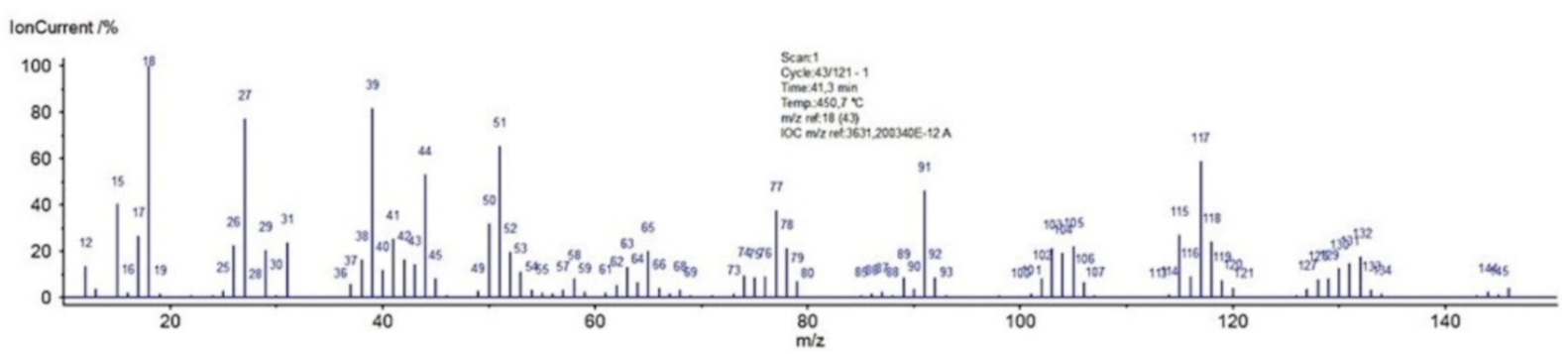

Figure 16. MS profiles registered during decomposition of DVB:TEVS = 1:1 after adsorption of P (a), 4-NP (b) and NB (c). 

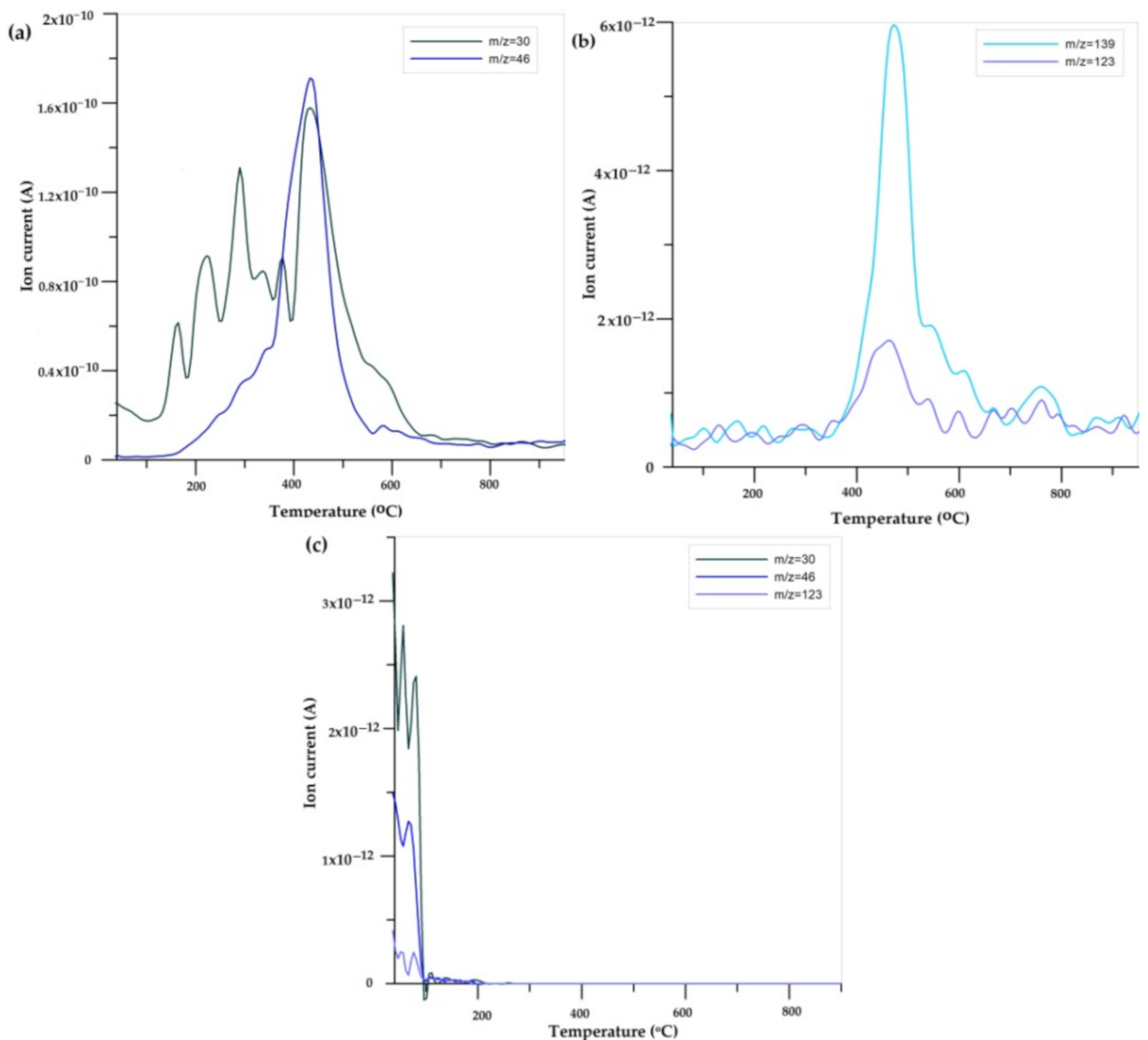

Figure 17. MS gaseous profiles registered during decomposition of DVB:TEVS $=1: 1$ after adsorption of 4 -NP $m / z=30$ and 46 (a) and $m / z=139$ and 123 (b) and of NB $m / z=30,46$ and 123 (c).

\section{Experimental and Calculation Procedures}

\subsection{Chemicals}

Triethoxyvinylsilane (TEVS), decan-1-ol and poly(vinyl alcohol) (PVA) were purchased in Fluka AG (Buchs, Switzerland). $\alpha, \alpha^{\prime}$-Azoiso-bis-butyronitrile (AIBN) and DVB (62.2\% of 1,4-divinylbenzene, $0.2 \%$ of 1,2-divinylbenzene and ethylvinylbenzene) were obtained from Merck (Darmstadt, Germany). Prior to use DVB and TEVS were washed with 3\% aqueous sodium hydroxide solution. Acetone and toluene have been obtained from Avantor Performance Materials Poland S.A. (Gliwice, Poland). The organic substances used in kinetic experiment: phenol and 4-nitrophenol were bought from Merck and the nitrobenzene from Avantor Performance Materials Poland S.A.

The structures of TEVS and DVB, as well as the model of the hybrid chain are shown in Figure 18. The properties of organic compounds used as the adsorbates in the kinetic studies are presented in Table 7. 


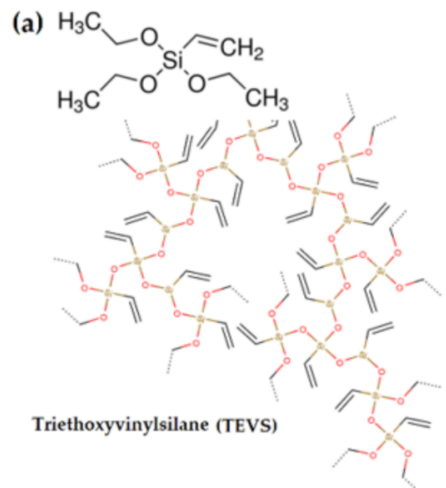

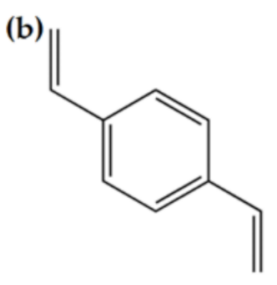

\section{1,4-divinylbenzene (DVB)}

(c)

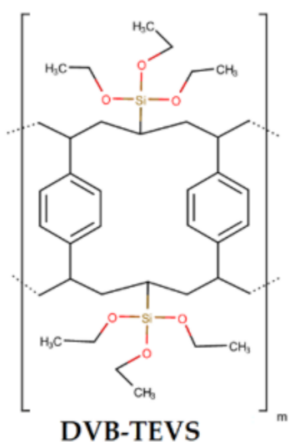

Figure 18. The chemical structure of inorganic (a) and organic (b) components of hybrid materials as well as the schematic structure of the copolymer (c).

Table 7. The physicochemical properties of used adsorbates.

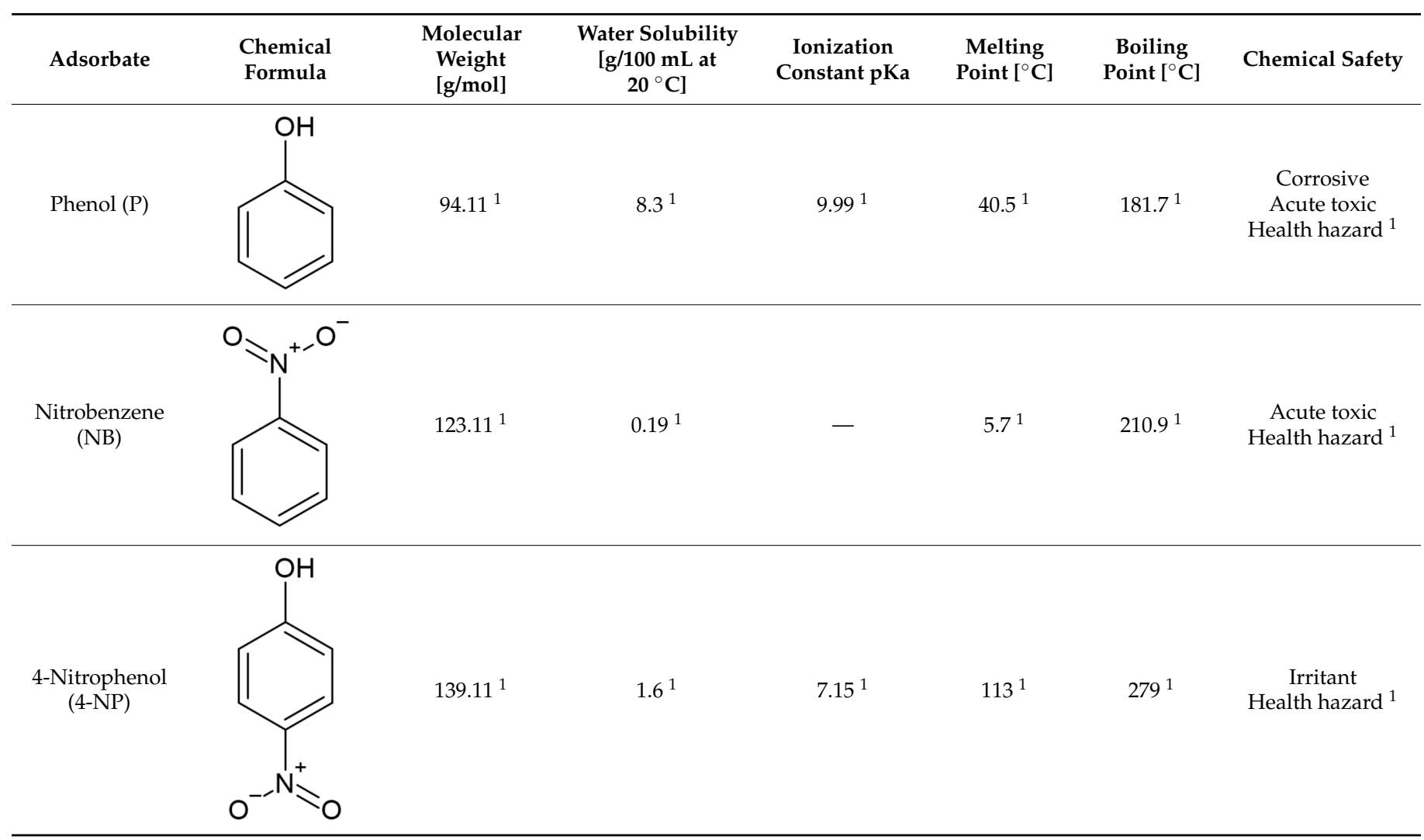

${ }^{1}$ https:/ / pubchem.ncbi.nlm.nih.gov (accessed on 01 February 2021).

\subsection{Materials Synthesis}

Copolymerization of 1,4-divinylbenzene with triethoxyvinylsilane was performed in the aqueous medium by using a suspension polymerization method. In synthesis vessel $75 \mathrm{~mL}$ of redistilled water and $1 \mathrm{~g}$ of poly(vinyl alcohol) were placed and stirred for $1 \mathrm{~h}$ at $80{ }^{\circ} \mathrm{C}$ in a three-necked flask fitted with a mechanical stirrer, thermometer and air cooler. Then, the solutions containing DVB and a corresponding amount of TEVS, the initiator AIBN (1 wt $\%)$ and the mixture of pore-forming diluents (toluene and 1-decanol, taken in $1 / 1(v / v)$ proportions) were added while stirring to the aqueous medium. The mixture was stirred at $350 \mathrm{rpm}$ for $12 \mathrm{~h}$ at $85^{\circ} \mathrm{C}$. The obtained microspheres were washed with distilled water (2 L), filtered, dried and extracted in a Soxhlet apparatus with boiling acetone for $3 \mathrm{~h}$. The amounts of individual components in reaction mixtures are presented in Table 8. 
Table 8. Compositions of reaction mixtures in organic-inorganic materials synthesis.

\begin{tabular}{|c|c|c|c|c|}
\hline \multirow{2}{*}{ Sample } & \multirow{2}{*}{\multicolumn{2}{|c|}{$\begin{array}{c}\text { Monomers } \\
\text { DVB-TEVS Molar Ratios }\end{array}$}} & \multicolumn{2}{|c|}{ Pore-Forming Diluents } \\
\hline & & & Toluene an & ames $\left[\mathrm{cm}^{3}\right]$ \\
\hline DVB:TEVS = 1:2 & 1 & 2 & 5 & 5 \\
\hline DVB:TEVS = 1:1 & 1 & 1 & 5 & 5 \\
\hline DVB:TEVS = 2:1 & 1 & 0.5 & 5 & 5 \\
\hline
\end{tabular}

\subsection{Investigation Methods}

\subsubsection{Scanning Electron Microscopy (SEM)}

The surface morphology of the samples was studied by the field emission Scanning Electron Microscopy (SEM) employing a Quanta ${ }^{\mathrm{TM}}$ 3D FEG (FEI Company, Hillsboro, OR, USA) apparatus operating at $5 \mathrm{kV}$. A high vacuum $\left(4 \times 10^{-4} \mathrm{~Pa}\right)$ mode was applied for imaging the investigated samples. Prior to measurement, the samples were mounted on aluminum stubs and sputtered with gold.

\subsubsection{Nitrogen Adsorption-Desorption Measurements}

The porosity of the materials was examined applying low-temperature nitrogen adsorption-desorption isotherms at $77 \mathrm{~K}$. The values of the parameters characterizing the properties of analyzed samples were obtained: the BET specific surface area $\left(\mathrm{S}_{\mathrm{BET}}\right)$ (assessed from the linear BET plot of adsorption data), the total pore volume $\left(\mathrm{V}_{\mathrm{t}}\right)$ (from the adsorption value at the relative pressure $p / p_{0} \sim 0.99$ ), the micropore volume $\left(\mathrm{V}_{\mathrm{mic}}\right)$ (from the t-plot), and the pore size distributions (PSD) followed by the Barrett, Joyner, and Halenda (BJH) procedure and the Non-Local Density Functional Theory (NLDFT) approach (ASAP 2020 analyzer, Micromeritics, USA Before the measurement, volatile materials adsorbed on the surface were driven by thermal degassing. In this procedure, the precisely weighed amount of the samples $(\sim 0.15 \mathrm{~g})$ were outgassed at $120^{\circ} \mathrm{C}$ and pressure of $1 \mathrm{mmHg}$ for $24 \mathrm{~h}$ in a degas port of analyser.

\subsubsection{Small-Angle X-ray Scattering (SAXS)}

Small X-ray scattering (SAXS) experiments were carried out by the Empyrean X-ray diffraction platforms (PANalytical), in transmission geometry $\mathrm{CuK} \alpha$ radiation with a wavelength $(\lambda)$ of $1.5418 \AA$ was used at $40 \mathrm{kV}$ and $40 \mathrm{~mA}$ configuration at room temperature. The $\mathrm{X}$-ray source consisted of an anode $\mathrm{Cu}$ source with a line focus type. SAXS measurements were performed using a $10 \mathrm{~mm}$ fixed mask, $\mathrm{Cu} 0.2 \mathrm{~mm}$ beam attenuator and PIXcel3D area detector. SAXS is an analytical technique that measures the $\mathrm{X}$-ray intensities scattered by a sample as a function of the scattering angle (scattering vector $\mathrm{q}$ ). Scattering vector $\mathrm{q}$ is given by $q=4 \pi \sin (\theta / 2) / \lambda$, where $\lambda$ is the wavelength of the $X$-ray beam and $\theta$ is the scattering angle. Measurements were made at a small angle in the range of 0.2 to $4.0 \mathrm{deg}$ of $2 \theta$.

The Porod approximation was applied to SAXS data processing to assess the interface between the matrix and the distracting objects (pores). Porod constant $\left(\mathrm{k}_{\mathrm{p}}\right)$ can be applied for determination of the specific surface area of the two-phase system using X-ray scattering at small-angle:

$$
\frac{\mathrm{S}}{\mathrm{V}}=\frac{4 \mathrm{p}(1-\mathrm{p}) \mathrm{k}_{\mathrm{p}}}{\mathrm{Q}_{\mathrm{p}}}
$$

where $p$ and (1-p) are the volumes of two phases, $k_{p}$ is the Porod's constant, and $Q_{p}$ is the Porod's invariant which is proportional to the mean-square density fluctuation of the whole scattering volume. If $S / V$ is calculated by $D_{v}(R)$ or Porod algorithm, the specific surface area from SAXS ( $\mathrm{S}_{\mathrm{SAXS}}$ ) can be calculated according to the equation:

$$
\mathrm{S}_{\mathrm{SAXS}}\left[\frac{\mathrm{m}^{2}}{\mathrm{~g}}\right]=\frac{10000 \cdot \frac{\mathrm{S}}{\mathrm{V}}\left[A^{-1}\right]}{\mathrm{d}\left[\frac{\mathrm{g}}{\mathrm{cm}^{3}}\right]}
$$


where $\mathrm{S} / \mathrm{V}$ is the surface divided by volume ratio calculated from the distribution curve and $\mathrm{d}$ is the mass density $[54,55]$.

\subsubsection{Fourier Transformed Infrared/Attenuated Total Reflection Analysis (FTIR/ATR)}

Fourier Transformed Infrared connected with Attenuated Total Reflection (FTIR/ATR) analysis was conducted by using IR spectrometer TENSOR 27 (Brucker, Germany) equipped with the diamond crystal. The spectra were recorded in the spectral range of $400-4000 \mathrm{~cm}^{-1}$.

\subsubsection{Thermal Analysis}

Thermal analysis was carried out on a TG/DTA/DSC apparatus (STA 449 Jupiter F1, Netzsch, Selb, Germany). Samples of mass $20 \mathrm{mg}$ placed in alumina crucibles and heated from 30 to $1200{ }^{\circ} \mathrm{C}$ under helium atmosphere with flow rate $50 \mathrm{~mL} \cdot \mathrm{min}^{-1}$ and heating rate $10^{\circ} \mathrm{C} \cdot \mathrm{min}^{-1}$. The gaseous products emitted during decomposition of materials after adsorption were analysed by Quadrupole Mass Spectroscopy (QMS 403C Aeölos, Selb, Germany). The QMS data in the range from 10 to 300 amu were recorded.

\subsubsection{Adsorption Studies}

Kinetic measurements were conducted using a UV-Vis spectrophotometer Cary 100 (Varian, Australia) with a flow working cell for periodic measurements of a solution concentration in a closed system. In all cases, $100 \mathrm{mg}$ of sample was placed in a quartz vessel connected with a stirrer $(110 \mathrm{rpm})$ and thermostatic system $\left(25^{\circ} \mathrm{C}\right)$ and filled with $100 \mathrm{~mL}$ solutes. Each of the samples was treated with three aqueous solutions of organic compounds: phenol, 4-nitrophenol, and nitrobenzene. The initial concentration of solutions in all cases was equal to $0.205 \mathrm{mmol} / \mathrm{L}$. At definite time intervals, the solution samples were gathered in a flow cell, and absorption spectra were measured, and the solution was turned back to the reaction vessel. The absorbance spectrum was recorded for wavelength ranges from 200 to $450 \mathrm{~nm}$. The concentration in the function of time profiles for the experimental systems was calculated from the recorded spectra.

The kinetic curves were analysed using several equations: first-order equation (FOE), the second-order equation (SOE) and pseudo first and second-order equations (PFOE and PSOE), the so-called mixed 1,2-order equation (MOE), the fractal-like MOE equation (f-MOE), the fractal-like first-order equation (f-FOE) and the fractal-like second-order equation (f-SOE), the so-called multiexponential equation (m-exp), the intraparticle diffusion model (IDM), and the pore diffusion model (PDM). The basic and pseudo first-order equations (FOE and PFOE can be expressed by a linear relationships (3) or (4):

$$
\ln \left(a_{e q}-a\right)=\ln \left(a_{e q}-a_{0}\right)-k_{1}
$$

where $\mathrm{a}$ is the temporary adsorbed amount, $a_{0}$ is the initial amount, $a_{e q}$ is the equilibrium adsorbed amount, $k_{1}$ is the adsorption rate coefficient.

$$
\ln \left(c_{e q}-c\right)=\ln \left(c_{e q}-c_{o}\right)-k_{1}
$$

where $c$ is the temporary adsorbate concentration, $c_{0}$ is the initial concentration, $c_{e q}$ is the equilibrium concentration, $k_{1}$ is the same as in Equation (3).

The second-order and pseudo second order equations (SOE and PSOE) can be noted as:

$$
a=a_{e q}\left[k_{2} t /\left(1+k_{2} t\right)\right]
$$

The linear forms of SOE and PSOE equations are:

$$
\begin{gathered}
t / a=\left(1 / a_{e q}\right)\left(1 / k_{2}+t\right) \\
a=a_{e q}-\left(1 / k_{2}\right)(a / t)
\end{gathered}
$$

where $k_{2}=k_{2 a} a_{e q}$ and $k_{2 a}$ are the rate coefficients for pseudo-second order kinetics. 
The generalization of the first and second order kinetics is the 1,2-mixed-order kinetic equation (MOE) which is the combination of the first and second order units and can be expressed as a relative adsorption progress in time $(F)$ :

$$
\begin{gathered}
F=a / a_{e q}=\frac{1-\exp \left(-k_{1} t\right)}{1-f_{2} \exp \left(-k_{1} t\right)} \\
\ln \left(\frac{1-F}{1-f_{2} F}\right)=-k_{1} t
\end{gathered}
$$

where $f_{2}<1$ is the normalized share of the second order process in the kinetics. In some cases, the MOE equation is reduced to the simple kinetic equations of the first $\left(f_{2}=0\right)$ and the second order $\left(f_{2}=1\right)$ type. Non-ideality effects can be considered using fractal-like equations ( $\mathrm{f}-\mathrm{FOE}, \mathrm{f}-\mathrm{SOE}$ and $\mathrm{f}-\mathrm{MOE}$ ) in which fractal coefficient $\mathrm{f}$ is used.

The multi-exponential equation (m-exp) is applied to describe numerous first-order processes or the follow up processes and has the following forms:

$$
\begin{aligned}
& c=\left(c_{\mathrm{o}}-c_{e q}\right) \sum_{i=1}^{n} f_{i} \exp \left(-k_{i} t\right)+c_{e q} \\
& c=c_{\mathrm{o}}-c_{\mathrm{o}} u_{e q} \sum_{i=1}^{n} f_{i}\left[1-\exp \left(-k_{i} t\right)\right]
\end{aligned}
$$

where $k_{i}$ is the rate coefficient, $u_{e q}=1-c_{e q} / c_{o}$ is the relative loss of adsorbate from the solution, and " $i$ " is the term of m-exp equation.

The Intraparticle Diffusion Model (IDM, Crank) characterizes the adsorption processes on the spherical adsorbent grains. When the concentration of adsorbate is constant the equation can be expressed as:

$$
F=1-\frac{6}{\pi^{2}} \sum_{n=1}^{\infty} \frac{1}{n^{2}} \exp \left(\frac{-\pi^{2} \cdot n^{2} \cdot D_{a} \cdot t}{r^{2}}\right)
$$

where $\mathrm{r}$ is the radius of adsorbent particle, $D_{a}$ is the effective diffusion coefficient and is given in equation:

$$
D_{a}=\frac{D}{\tau_{p} \cdot\left(1+\rho \cdot K_{H} \cdot \varepsilon_{p}\right)}
$$

where $D$ is the molecular diffusion coefficient, $\tau_{p}$ is the dimensionless pore tortuosity factor, $\rho$ is the particle density, $\varepsilon_{p}$ is the particle porosity and $K_{H}$ is the Henry adsorption constant.

The Pore Diffusion Model (PDM, McKay) describe adsorption on porous solids which combines the transfer resistance of adsorbate particles through the surface layer, the proportional penetration of the adsorbate into the adsorbent grains, the sharp boundary between the space in which the equilibrium state is determined and the space without the adsorbate, and can be expressed by the mathematic formula:

$$
\frac{d F}{d \tau_{s}}=\frac{3\left(1-u_{e q} \cdot F\right) \cdot(1-F)^{\frac{1}{3}}}{1-B \cdot(1-F)^{\frac{1}{3}}}
$$

where $u_{e q}$ is the relative adsorbate loss, the parameter $B=1-1 / B_{i}$ and $B_{i}=K_{f} / D_{p}$ is the Biot number, $D_{p}$ is the pore diffusion coefficient, $K_{f}$ is the external mass transfer coefficient, $\tau_{s}$ is the undersized model time $[32,56,57]$.

\section{Conclusions}

Divinylbenzene-co-triethoxyvinysilane microspheres were synthesized at different component molar ratios (DVB:TEVS = 1:2, DVB:TEVS = 1:1 and DVB:TEVS = 2:1). The obtained materials were characterized by differentiated morphology and porosity. The DVB:TEVS = 1:2 microspheres showed many deviations from the ideal spherical form, while the DVB:TEVS = 2:1 microspheres were characterized by the most regular shape, uniform and smooth surface. FTIR/ATR spectroscopy confirmed the incorporation of TEVS into 
the polymeric structure of the synthesized materials. The SAXS and nitrogen adsorptiondesorption techniques produced similar results regarding the structural characteristics of the copolymers. The specific surface areas determined by both methods were similar with slight differences indicating a low amount of closed porosity. The correlation between the structure parameters (specific surface area and pore total volume) and DVB:TEVS ratio was found.

The adsorption properties of the synthesized microspheres towards nitrobenzene, 4-nitrophenol and phenol were studied by kinetic measurements. Generally, the differences in the amount and rate of concentration loss from the solutions of all solutes were observed. For all tested materials the strongest decrease of adsorbate concentration was found for nitrobenzene, and the lowest for phenol which was connected with adsorbate solubility/hydrophobicity. For nitrobenzene adsorption the greatest adsorbate losses from the solution were observed in the case of the most hydrophobic DVB:TEVS = 2:1, however, for 4-nitrophenol and phenol adsorption the greatest adsorbate losses were found for DVB:TEVS $=1: 1$. The adsorption effectiveness of DVB:TEVS $=2: 1$ and DVB:TEVS $=1: 2$ materials towards different adsorbates was similar, however, DVB:TEVS $=1: 1$ showed quite different properties. The measured kinetic profiles revealed the global effect of several factors: the hydrophobic/hydrophilic properties, the structural adsorbent characteristics, the polymer swelling, the adsorbent-adsorbate interactions.

The thermal analysis proved that the synthesized DVB-TEVS materials were thermally stable up to at least $330{ }^{\circ} \mathrm{C}$, thus, they may be applied in relatively wide temperature ranges. The weight losses for all materials with adsorbed organic solutes were higher in comparison to pure DVB-TEVS materials suggesting relatively weak adsorbent-adsorbate interactions of physical nature. The MS gaseous profiles revealed certain amounts of nitrogen compounds confirming adsorption of 4-nitrophenol and nitrobenzene.

The synthesized polymeric materials showed remarkable selectivity towards various organic adsorbates confirmed by divergent uptakes and kinetic characteristics. They seem to be promising materials for adsorption and separation techniques.

Supplementary Materials: The following are available online. Figure S1: FTIR/ATR spectra of DVB, Figure S2: Adsorption kinetics for NB (a), P (b) and 4-NP (c) on DVB:TEVS = 2:1, DVB:TEVS = 1:2 and DVB:TEVS = 1:1 presented as changes in concentration over time, Figure S3: TG/DTG/DSC curves of DVB, Figure S4: 3D MS profile of thermal decomposition of DVB, Figure S5: MS spectra of thermal degradation of DVB at $450{ }^{\circ} \mathrm{C}$ and Figure S6: MS profiles of gaseous products of thermal degradation of DVB:TEVS $=1: 1$ and DVB $(\mathrm{m} / \mathrm{z}=189)$.

Author Contributions: Conceptualization, A.B, M.Z.-S., A.D.-M. and B.P.; Material synthesis, B.P.; Investigation, A.B., M.Z.-S. and M.W.; Methodology, A.B., M.Z.-S., M.W. and A.D.-M., Supervision, A.D.-M. and M.Z.-S.; Writing-original draft, A.B.; M.Z.-S., A.D.-M. and M.W. Writing-review and editing, A.B., A.D.-M., M.Z.-S., M.W. and B.P. All authors have read and agreed to the published version of the manuscript.

Funding: This research received no external funding.

Institutional Review Board Statement: Not applicable.

Informed Consent Statement: Informed consent was obtained from all subjects involved in the study.

Data Availability Statement: The data are available by corresponding author.

Conflicts of Interest: The authors declare no conflict of interest.

Sample Availability: Samples of the compounds are available from the authors.

\section{References}

1. Chujo, Y. Organic-inorganic hybrid materials. Curr. Opin. Solid State Mater. Sci. 1996, 1, 806-811. [CrossRef]

2. Tiwari, I.; Mahanwar, P.A. Polyacrylate/silica hybrid materials: A step towards multifunctional properties. J. Dispers. Sci. Technol. 2019, 40, 925-957. [CrossRef]

3. Saha, P.; Chowdhury, S.; Kim, M.C.; Kim, J.K. MultiComponent Materials. In Multicomponent Polymeric Materials, 1st ed.; Kim, J.K., Thomas, S., Saha, P., Eds.; Springer: Dordrecht, The Netherlands, 2016; Volume 223, pp. 3-12. 
4. Timin, A.; Rumyantsev, E.; Solomonov, E. Synthesis and application of amino-modified silicas containing albumin as hemoadsorbents for bilirubin adsorption. J. Non-Cryst. Solids 2014, 385, 81-88. [CrossRef]

5. Kubota, Y.; Nishizaki, Y.; Ikeya, H. Organic-silicate hybrid catalysts based on various defined structures for Knoevenagel condensation. Microporous Mesoporous Mater. 2004, 70, 135-149. [CrossRef]

6. Gomez-Romero, P. Hybrid Organic-Inorganic Materials-In Search of Synergic Activity. Adv. Mater. 2001, 13, 163-174. [CrossRef]

7. Kawaguchi, H. Functional polymer microspheres. Prog. Polym. Sci. 2000, 25, 1171-1210. [CrossRef]

8. Wang, Z.; Lei, F.; Li, W.; Li, P.; Wang, T.; Qin, L.; Cheng, G.; Sun, Y. Preparationof rosin-based polymer microspheres as a stationary phase inhigh-performance liquid chromatography to separate polycyclic aromatic hydrocarbons and alkaloids. e-Polymers 2019, 19, 290-296. [CrossRef]

9. Schmidt, G.; Malwitz, M.M.; Shankar, R. Properties of polymer-nanoparticle composites. Curr. Opin. Colloid Interface Sci. 2003, 8, 103-108. [CrossRef]

10. Mammeri, F.; Le Bourhis, E.; Rozes, L.; Sanchez, C. Mechanical properties of hybrid organic-inorganic materials. J. Mater. Chem. 2005, 15, 3789-3811. [CrossRef]

11. Lu, S.; Chun, W.; Yu, J.; Yang, X. Preparation and Characterization of the Mesoporous $\mathrm{SiO}_{2}-\mathrm{TiO}_{2}$ / Epoxy Resin Hybrid Materials. J. Appl. Polym. Sci. 2008, 109, 2095-2102. [CrossRef]

12. Zoppi, R.A.; DeCastro, C.R.; Yoshida, I.V.P. Hybrids of $\mathrm{SiO}_{2}$ and poly(amide6-b-ethyleneoxide). Polymer 1997, $38,5708-5712$. [CrossRef]

13. Causin, V. Polymers: An Overview. In Polymers on the Crime Scene, 1st ed.; Causin, V., Ed.; Springer: Cham, Switzerland, 2015; pp. 9-52.

14. Mascia, L.; Capra, C.; Lavorgna, M. Organic-Inorganic Hybrid Fillers for the Controlled Release of Antioxidants. Macromol. Symp. 2007, 247, 129-139. [CrossRef]

15. Ogoshi, T.; Chujo, Y. Synthesis of anionic polymer-silica hybrids by controlling $\mathrm{pH}$ in an aqueous solution. J. Mater. Chem. 2005, 15, 315-322. [CrossRef]

16. Yap, H.Y.; Soon, C.F.; Nor, N.H.M.; Saripan, M.S.; Sahdan, M.Z.; Tee, K.S. Synthesis and characterization of polymeric microspheres by using suspension polymerization technique. ARPN J. Eng. Appl. Sci. 2016, 11, 11808-11811.

17. Santos, J.C.; Lopes, C.N.; Reis, M.M.; Giudici, R.; Sayer, C.; Machado, R.A.F.; Araujo, P.H.H. Comparison of techniques for the determination of conversion during suspension polymerization reactions. Braz. J. Chem. Eng. 2008, 25, 399-407. [CrossRef]

18. Bansal, H.; Kaur, S.P.; Gupta, A.K. Microsphere methods of preparation and applications; a comparative study. Int. J. Pharm. Sci. Rev. Res. 2011, 10, 69-78.

19. Lebedev, E.V. Hybrid organic-inorganic polymer systems: Synthesis, structure, and properties. Theor. Exp. Chem. 2011, 46, 5708-5712. [CrossRef]

20. Mahfouz, M.G.; Killa, H.M.; Sheta, M.E.; Moustafa, A.H.; Tolba, A.A. Synthesis, characterization, and application of polystyrene adsorbents containing tri-n-butylphosphate for solid-phase extraction of uranium(VI) from aqueous nitrate solutions. J. Radioanal. Nucl. Chem. 2016, 309, 729-741. [CrossRef]

21. Maciejewska, M. Characterization of macroporous1-vinyl-2-pyrrolidone copolymers obtained by suspension polymerization. J. Appl. Polym. Sci. 2011, 124, 568-575. [CrossRef]

22. Ali, S.W.; Malik, M.A.; Yasin, T. Economical and environmentally friendly synthesis of strongcation-exchange resins frommacroporous styrene-divinylbenzene copolymers. Polym. Bull. 2016, 73, 559-570. [CrossRef]

23. Srivastava, S.; Zare, E.N.; Makvandi, P.; Zheng, X.; Iftekhar, S.; Wu, A.; Padil, V.V.T.; Mokhtari, B.; Varma, R.S.; Tay, F.R.; et al. Cytotoxic aquatic pollutants and their removal by nanocomposite-based sorbents. Chemosphere 2020, 258, 127324. [CrossRef]

24. Younas, F.; Mustafa, A.; Faroogi, Z.U.R.; Wang, X.; Younas, S.; Mohy-Ud-Din, W.; Hameed, M.A.; Abrar, M.M.; Maitlo, A.A.; Noree, S.; et al. Current and Emerging Adsorbent Technologies for Wastewater Treatment: Trends, Limitations, and Environmental Implications. Water 2021, 13, 215.

25. Sheth, Y.; Dharaskar, S.; Khalid, M.; Sonawane, S. An environment friendly approach for heavy metal removal from industrial wastewater using chitosan based biosorbent: A review. Sustain. Energy Technol. Assess. 2021, 43, 100951.

26. Aldawsari, A.M.; Alsohaimi, I.; Hassan, H.M.A.; Abdalla, Z.E.A.; Hassan, I.; Berber, M.R. Tailoring an efficient nanocomposite of activated carbon-layered double hydroxide for elimination of water-soluble dyes. J. Alloy. 2021, 857, 157551. [CrossRef]

27. Karimi-Maleh, H.; Ayati, A.; Davoodi, R.; Tanhaei, B.; Karimi, F.; Malekmohammadi, S.; Orooji, Y.; Fu, L.; Sillanpää, M. Recent advances in using of chitosan-based adsorbents for removal of pharmaceutical contaminants: A review. J. Clean. Prod. 2021, 291, 125880. [CrossRef]

28. Kambarova, E.A.; Gawrilenko, M.A.; Bektenov, N.A. Zeolites modified with polyethylenepolyamine and epoxy resin to extract lead ions from wastewater. Bull. Tomsk Polytech. Univ. Geo Assets Eng. 2021, 1, 7-13.

29. Wang, M.; Gengxian, L.; Chunlong, X.; Xudong, J.; Rubing, W.; Qingquan, L.; Xiyun, C. Facile preparation of cyclodextrin polymer materials with rigid spherical structure and flexible network for sorption of organic contaminants in water. Chem. Eng. J. 2021, 411, 128489. [CrossRef]

30. Budnyak, T.M.; Błachnio, M.; Slabon, A.; Jaworski, A.; Tertykh, V.A.; Derylo-Marczewska, A.; Marczewski, A.W. Chitosan Coated Silica as Effective and Sustainable Material for Acid Orange 8 Dye Capturing: Effect of Temperature in AdsorptionEquilibrium and Kinetics. J. Phys. Chem. C 2020, 28, 15312-15323. [CrossRef] 
31. Derylo-Marczewska, A.; Blachnio, M.; Marczewski, A.W.; Swiatkowski, A.; Buczek, B. Adsorption of chlorophenoxy pesticides on activated carbon with gradually removed external particle layers. Chem. Eng. J. 2017, 308, 408-418. [CrossRef]

32. Blachnio, M.; Derylo-Marczewska, A.; Charmas, B.; Zienkiewicz-Strzalka, M.; Bogatyrov, V.; Galaburda, M. Active Carbonfrom Agricultural Wastes for Adsorption of Organic Pollutants. Moelcules 2020, 25, 5105. [CrossRef]

33. Blachnio, M.; Derylo-Marczewska, A.; Marczewski, A.W.; Seczkowska, M. Phenoxyacid pesticide adsorption on activatedcarbonequilibrium and kinetics. Chemosphere 2019, 214, 349-360.

34. Derylo-Marczewska, A.; Marczewski, A.W. Effect of adsorbate structure on adsorption from solutions. Appl. Surf. Sci. 2002, 196, 264-272. [CrossRef]

35. Derylo-Marczewska, A.; Miroslaw, K.; Marczewski, A.W.; Sternik, D. Studies of adsorption equilibria and kinetics of o-,m-,pnitro-and chlorophenols on microporous carbons from aqueous solutions. Adsorption 2010, 16, 359-375. [CrossRef]

36. Podkoscielna, B.; Sobiesiak, M. Synthesis and characterization of organic-inorganic hybrid microspheres. Adsorption 2016, 22, 631-638. [CrossRef]

37. Podkoscielna, B.; Fila, K.; Gil, M.; Nowak, J. Synthesis and characterization of new hybrid microspheres with amide functionalization. Adsorpt. Sci. Technol. 2017, 35, 422-431. [CrossRef]

38. Goliszek, M.; Poskoscielna, B.; Fila, K.; Riazanova, A.V.; Aminzadeh, S.; Sevastyanova, O.; Gunko, V.M. Synthesis and structure characterization of polymeric nanoporous microspheres with lignin. Cellulose 2018, 25, 5843-5862. [CrossRef]

39. Fila, K.; Bolbukh, Y.; Goliszek, M.; Podkoscielna, B.; Gargol, M.; Gawdzik, M. Synthesis and characterization of mesoporous polymeric microspheres of methacrylic derivatives of aromatic thiols. Adsorption 2019, 35, 429-442. [CrossRef]

40. Podkoscielna, B.; Kolodynska, D.; Podkoscielny, P. Chemical modification of commercial St-DVB microspheres and their application for metal ions removal. Adsorption 2019, 25, 529-544. [CrossRef]

41. Santa Maria, L.C.; Costa, M.A.S.; Santos, F.A.M.; Wang, S.H.; Silva, M.R. Preparation and characterization of polymer metalcomposite microspheres. Mater. Lett. 2006, 60, 270-273. [CrossRef]

42. Wawrzykiewicz, M.; Podkoscielna, B.; Podkoscielny, P. Application of Functionalized DVB-co-GMA Polymeric Microspheres in the Enhanced Sorption Process of Hazardous Dyes from Dyeing Baths. Molecules 2020, 25, 5247. [CrossRef]

43. Hamid, J.N.; Fariba, D.; Reza, M.A. Effects of triethoxy and triphenylvinylsilanes on the porous structure of cross-linked poly(methylmethacrylate) beads. e-Polymers 2008, 1-11. [CrossRef]

44. Naghash, H.; Karimzadeh, A.; Momeni, A.; Massah, A.; Alian, H. Preparation and Properties of Triethoxyvinylsilane-Modified Styrene-Butyl Acrylate Emulsion Copolymers. Turk. J. Chem. 2007, 31, 257-269.

45. Lee, J.; Hwang, D.; Shim, S.; Rhym, Y.-M. Controlling Morphology of Polymer Microspheres by Shirasu Porous Glass (SPG) Membrane Emulsification and Subsequent Polymerization: From Solid to Hollow. Macromol. Res. 2010, 18, 1142-1147. [CrossRef]

46. Yu, B.; Xu, T.; Cong, H.; Peng, Q.; Usman, M. Preparation of Porous Poly(Styrene-Divinylbenzene) Microspheres and TheirModification with Diazoresin for Mix-Mode HPLC Separations. Materials 2017, 10, 440. [CrossRef]

47. Walenta, E. Small angle X-ray scattering. Acta Polym. 1985, 36, 296. [CrossRef]

48. Li, T.; Senesi, A.J.; Lee, B. Small Angle X-ray Scattering for Nanoparticle Research. Chem. Rev. 2016, 116, 11128-11180. [CrossRef]

49. Putnam, C.D.; Hammel, M.; Hura, G.L.; Tainer, J.A. X-ray solution scattering (SAXS) combined with crystallography andcomputation: Defining accurate macromolecular structures, conformations and assemblies in solution. Q. Rev. Biophys. 2007, 40, 191-285. [CrossRef]

50. McDermott, A.G.; Budd, P.M.; McKeown, N.B.; Colina, C.M.; Runt, J. Physical aging of polymers of intrinsic microporosity: A SAXS/WAXS study. J. Mater. Chem. A 2014, 2, 11742-11752. [CrossRef]

51. Saurel, D.; Segalini, J.; Jauregui, M.; Pendashteh, A.; Daffos, B.; Simon, P.; Casas-Cabanas, M. A SAXS outlook on disorderedcarbonaceous materials for electrochemical energy storage. Energy Storage Mater. 2019, 21, 162-173. [CrossRef]

52. Williams, J.A.; Rindone, G.E.; Mckinstry, H.A. Small-Angle X-Ray Scattering Analysis of Nucleation in Glass: I Matrix Scattering and Sample Surface Effects. J. Am. Ceram. Soc. 1981, 64, 697-702. [CrossRef]

53. Sharma, J. Characterization of Polymer Blends by X-Ray Scattering: SAXS and WAXS. In Characterization of Polymer Blends; Thomas, S., Grohens, Y., Jyotishkumar, P., Eds.; Wiley Online Library: New York, NY, USA, 2014; pp. 209-236.

54. Zienkiewcz-Strzalka, M.; Pikus, S. The study of palladium ions incorporation into the mesoporous ordered silicates. Appl. Surf. Sci. 2012, 261, 616-622. [CrossRef]

55. Zienkiewcz-Strzalka, M.; Pikus, S. Synthesis of photoactive AgCl/SBA-15 by conversion of silver nanoparticles into stable AgCl nanoparticles. Appl. Surf. Sci. 2013, 265, 904-911. [CrossRef]

56. Marczewski, A.W.; Derylo-Marczewska, A.; Slota, A. Adsorption and desorption kinetics of benzene derivatives on mesoporous carbons. Adsorption 2013, 19, 391-406. [CrossRef]

57. Chrzanowska, A.; Derylo-Marczewska, A.; Wasilewska, M. Mesocellular SilicaFoams (MCFs) with Tunable Pore Size as a Support for Lysozyme Immobilization: Adsorption Equilibrium and Kinetics, Biocomposite Properties. Mol. Sci. 2020, 21, 5479. [CrossRef] 